\title{
Uptake of dissolved inorganic nitrogen by shallow seagrass communities exposed to wave-driven unsteady flow
}

\author{
J. S. Weitzman ${ }^{1, *}$, K. Aveni-Deforge ${ }^{2}$, J. R. Koseff ${ }^{1}$, F. I. M. Thomas ${ }^{2}$ \\ ${ }^{1}$ Department of Civil and Environmental Engineering, Stanford University, Stanford, California 94305, USA \\ ${ }^{2}$ Hawaii Institute of Marine Biology, University of Hawai'i, Mānoa, Kāne'ohe, Hawai'i 96744, USA
}

\begin{abstract}
In natural seagrass systems, regular oscillatory motion-like that caused by surface wind-waves - enhances uptake of dissolved inorganic nitrogen (DIN) relative to current-driven, unidirectional flows. A mobile field flume was deployed to measure the uptake of DIN by intact shallow seagrass communities exposed to unidirectional, oscillatory, and combined flows. The flume volume was spiked with ${ }^{15} \mathrm{~N}$-labeled DIN to measure nutrient uptake rate constants for the entire system $(S)$ and to determine height-specific nutrient uptake rates of seagrass epiphytes $(\rho)$. In oscillatory and combined flows, $S$ depended positively on the water speed, but also inversely on a modified Keulegan-Carpenter number (KC). This ratio compares the wave-orbital excursion distance to canopy element spacing. Experiments characterized by relatively low KC values were associated with significantly higher uptake efficiencies than experiments characterized by high $\mathrm{KC}$ values. Uptake efficiencies for high $\mathrm{KC}$ conditions were similar to those measured in comparable unidirectional flows. Measured canopy flow attenuation was also found to increase with $\mathrm{KC}$, a result in line with expectations from a parameterized conceptual model. Damping variability alone could not explain the observed oscillatory flow uptake enhancement however, a result that seemingly highlights the role of both element flexural response and unsteady boundary layer mechanics in the exchange process. In all flow conditions, DIN uptake rates of epiphytes harvested from the bottom of the blades $\left(\rho_{\text {bot }}\right)$ were lower than those for epiphytes harvested from the upper portion of the blades $\left(\rho_{\text {top }}\right)$. While uptake by the top epiphytes exhibited flow dependency, uptake by bottom epiphytes did not.
\end{abstract}

KEY WORDS: Seagrass $\cdot$ Uptake $\cdot$ Waves

Resale or republication not permitted without written consent of the publisher

\section{INTRODUCTION}

In current-driven flows, seagrass community uptake rates of dissolved inorganic nitrogen (DIN) are consistent with theory describing mass transfer limited (MTL) exchange (Thomas et al. 2000, Cornelisen \& Thomas 2002, 2004, 2006, Thomas \& Cornelisen 2003). Under MTL conditions, uptake rates are determined solely by physical properties and interactions like fluid velocity, canopy drag, and surface roughness. Relying on an analogy between MTL uptake and MTL dissolution, researchers have employed semi-empirical heat and mass transfer models to successfully predict mass transfer rates from a variety of benthic bottom roughness types, including both coral and seagrass communities (Thomas \& Atkinson 1997, Thomas et al. 2000, Falter et al. 2004).

Many seagrass communities are also exposed to oscillatory fluid motion caused by wind-driven surface waves (Fonseca \& Cahalan 1992). Direct measurements have shown that rates of nutrient uptake by seagrass in oscillatory flows exceed rates mea- 
sured in unidirectional flows with ostensibly similar freestream bulk flow statistics (Thomas \& Cornelisen 2003). Similar increases in wave-driven mass transfer have been seen in gypsum dissolution experiments with coral skeletons, idealized cylindrical elements, and roughened box models (Falter et al. 2005, Lowe et al. 2005b, Reidenbach et al. 2006). While numerous experiments using mass dissolution in rigid canopies have been used to illustrate the mechanisms that drive scalar transport (Falter et al. 2005, Lowe et al. 2005b, Reidenbach et al. 2006) and a core set of experiments with flexible grass and grass models have been used to elucidate seagrass flow patterns (Koch 1996, Ghisalberti \& Nepf 2002, Luhar et al. 2008, Lacy \& Wyllie-Echeverria 2011), direct measurements of wave-driven nutrient uptake in seagrass communities are especially rare and important for both validation and theory advancement.

The experiments described here were designed to address this deficiency with a new and comprehensive methodology. We used a field-deployable racetrack flume to investigate wave-driven canopy flow and uptake directly, employing an isotopic tracer method to track how vertical hydrodynamic variability determines the vertical distribution of uptake among seagrass epiphytes. Our findings illuminate the importance of oscillatory frequencies to wavedriven benthic uptake and highlight the complexities that element flexibility adds to existing mass transfer theory.

\section{Canopy mass exchange and nutrient uptake}

The interaction between water column hydrodynamics and submerged vegetated canopies affects the coupling of benthic and pelagic nutrient cycling (Lemmens et al. 1996, Thomas et al. 2000, Morris et al. 2008) and affects stresses imposed at the sediment/ water interface (Fonseca \& Fisher 1986, Fonseca \& Cahalan 1992, Gacia et al. 1999). Seagrass communities provide important ecosystem services: they filter the water column (Szmant \& Forrester 1996, Lapointe et al. 2004), feed grazing marine species (Fry \& Parker 1979, Moncreiff et al. 1992, Connolly et al. 2005), and shelter organisms during early stages of their development (Eggleston et al. 2004, Gullström et al. 2008).

The total mass flux per unit time $(J)$ between a surface and a passing flow is classically parameterized using the difference in mass concentration between the passing fluid $\left(C_{\infty}\right)$ and at the transfer surface $\left(C_{0}\right)$ as well as a representative mass transfer coefficient $S$ (Falter et al. 2005, Lowe et al. 2005b):

$$
J=S\left(C_{\infty}-C_{0}\right)
$$

In the case of MTL nutrient uptake by a biotic surface, nutrient utilization rates match nutrient diffusion rates across surface boundary layers, and surface concentrations are effectively zero (i.e. $C_{0}=0$, 'perfect sink'). Eq. (1) thus simplifies to:

$$
J=S C_{\infty}
$$

The uptake efficiency of a MTL surface is typically expressed by the Stanton number:

$$
\mathrm{St}=\frac{S}{U}
$$

a non-dimensional parameter that relates the uptake rate coefficient to rate of fluid advection, here shown as a scale velocity $U$ (Bilger \& Atkinson 1995, Thomas et al. 2000, Lowe et al. 2005b).

The exact value of $S$ is shaped by a suite of factors, among them the underlying rate of advection (through $U)$, the fluid viscosity (v), the substance's molecular diffusivity in the fluid $(D)$, utilization or generation of the substance at the transfer surface, and interaction of flow and the surface (drag and shear). Implicit in this parameter are the effects all these interactions have on boundary layer thicknesses $(\delta)$ and, ultimately, the diffusive processes. This conceptual framework depends on film theory, which posits that the relatively slow diffusive processes at surface boundary layers are the primary limit on exchange rates (Nishihara \& Ackerman 2009). In this context, flow acts both to carry material to and from the edge of these layers and to thin the layers, reducing the diffusive distance between the boundary layer edge and the exchange surface (Larned et al. 2004).

Canopy-scale mass exchange can be understood as a composite process, the net result of individual, element-scale interactions (Lowe et al. 2005b). It can be represented by a dual functional dependence: one function, $f$, representing fluid and surface interaction at the element scale, and another, $g$, representing the geometric characteristics of the array these elements form:

$$
S \alpha f\left(\widehat{\operatorname{Re}}_{e}, \mathrm{Sc}\right) \cdot g\left(\lambda_{\mathrm{F}}, \lambda_{\mathrm{P}}\right)
$$

Here, fluid/surface interaction is quantified by the Reynolds number of flow within the canopy $\left(\widehat{\operatorname{Re}}_{e}=\widehat{U}_{\mathrm{s}} d / v\right)$ and the Schmidt number $(\mathrm{Sc}=v / D)$, which quantifies the ratio of molecular diffusivities. The length scale $d$ is a representative element width or diameter and $\widehat{U}_{\mathrm{s}}$ is the canopy depth-averaged fluid speed. (The overhat will be used throughout to denote 
a canopy depth-averaged quantity.) Canopy geometry is described by a pair of non-dimensional quantities, one that captures the frontal area per bed area $\left(\lambda_{\mathrm{F}}\right)$ and another for the planar area per bed area $\left(\lambda_{\mathrm{P}}\right)$. In water, Sc depends on the specific molecular species under consideration (through $D$ ) as well as water temperature and salinity (through both $D$ and $v$ ). Sc is a consistent value when water properties and the metabolic species are held within a fairly narrow range.

Eqs. (2) \& (4) above show that uptake ultimately depends on both the local mass concentrations and the local velocities within the canopy space. Much then relies on the measurement or prediction of these properties. In well-mixed conditions, the volumeaveraged mass concentration within the canopy can be taken to be equal to the concentration in the freestream, indicated as $C_{\infty}$ above. Lowe et al. (2005b) demonstrated through a scaling argument that wellmixed conditions can be expected in dense model canopies under even the weakest of currents. Extension of the assumption to these natural canopies will be considered below. Critically, however, the specifics of canopy flow depend on complex interactions between the momentum of imposed fluid flow and the resistance applied by the canopy elements.

\section{Canopy flow model}

The force balance that determines in-canopy velocities depends on 3 factors: a shear stress imposed at the top of the canopy, drag exerted by the canopy, and-when waves are present-the inertial forces associated with that unsteadiness (Lowe et al. 2005a, Luhar et al. 2010). Luhar et al. (2010) applied and streamlined the full rigid-canopy momentum balance model introduced by Lowe et al. (2005a) to the case of a model canopy comprised of flexible elements. In each of these approaches, canopy depth-averaged flow $(\widehat{U})$ is described relative to undisturbed abovecanopy flow $\left(U_{\infty}\right)$ with the velocity ratio:

$$
\alpha=\frac{\widehat{U}}{U_{\infty}}
$$

This ratio is expressed in terms of component-wise values:

$$
\alpha_{\mathrm{w}}=\frac{\widehat{U}_{\mathrm{w}}}{U_{\infty, \mathrm{w}}}
$$

based on the root mean square (rms) velocities of the waves $(\mathrm{w})$, and:

$$
\alpha_{\mathrm{c}}=\frac{\widehat{U}_{\mathrm{c}}}{U_{\infty, \mathrm{c}}}
$$

based on time-averaged mean currents (c). In combined flows, we also consider:

$$
\alpha_{\mathrm{s}}=\frac{\widehat{U}_{\mathrm{s}}}{U_{\infty, \mathrm{s}}}
$$

based on the total speed (s), the result of both steady and unsteady motions. The Lowe et al. (2005a) model allows one to predict $\widehat{U}$ using combined information about the freestream conditions, canopy geometry, and the canopy/flow interactions. Details of this model and its application appear in Appendix 1.

\section{Element flexibility}

Even with a measured or predicted time-averaged canopy flow magnitude in hand, potentially vital information about the relative unsteadiness of fluid and element motion is left out of the associated uptake parameterization (Eq. 4). Unlike the rigid surfaces formed by corals, flexible macrophytes respond dynamically to the forces imposed by fluid motion. Elements flutter, flap, pronate, and realign in response to local velocity fluctuations and larger scale unsteadiness like that associated with passing waves. These motions can act to repeatedly thin and even temporarily remove surface boundary layers, exposing tissue to pulses of nutrient-laden fluid (Koch 1994, Denny \& Roberson 2002). These phenomena have been linked to a mass flux enhancement effect, the magnitude of which depends on the frequency of these disturbances. The timeaveraged flux rises dramatically if the disturbance rate outpaces the renewal rate of the surface boundary layers (Huang et al. 2011). In steady flow, the scale and timing of the events depend primarily on element morphology, rigidity, and surface roughness (Koch 1994). In oscillatory flow, these effects are compounded by the repeated reorientation of the flow field and the elements within it (Stevens et al. 2003). As the wave frequency increases so too does the unsteady mass transfer enhancement effect.

\section{Keulegan-Carpenter parameter}

An approach that predicts nutrient exchange using only time-averaged wave velocities would therefore underestimate the important contribution that the rate of oscillation makes to the overall mass transfer rate (Stevens et al. 2003). We note, however, that the governing forces of canopy wave attenuation can be expressed by a modified form of the Keulegan-Carpenter parameter, KC (Lowe et al. 2005a). The standard form of this non-dimensional ratio has tradition- 
ally been used to gauge the relative importance of drag and inertial forces experienced by a solitary, wave-exposed object. It compares the scale of wave orbital excursions $\left(A_{\infty, \mathrm{w}}\right)$ to the relevant geometric scale of the object $(d)$ (Keulegan \& Carpenter 1958, Dean \& Dalrymple 1991, Monismith 2007). The KC parameter was repurposed for canopy flow in Lowe et al. (2005a). We identify their ratio-defined in terms of the element-to-element spacing $(s)$ - as a modified Keulegan-Carpenter parameter:

$$
\mathrm{KC}^{*}=\frac{A_{\infty, \mathrm{w}}}{S}
$$

Here, the orbital excursion distance is:

$$
A_{\infty, \mathrm{w}}=\frac{U_{\infty, \mathrm{w}}}{\omega}
$$

in which the orbital frequency, $\omega=2 \pi / T$ and $T$ is the wave period. In this modified form, the orbital scale is compared to a canopy void scale. $\mathrm{KC}^{*}$ ties together the primary factors that damp oscillatory motion in the canopy space-namely, the size of wave-generated orbitals and the distance between elements. In low $\mathrm{KC}^{*}$ conditions, orbital excursion distances are small relative to inter-element distances and flow reduction is minimized; at the opposite extreme, canopy drag dominates and wave-driven flow is greatly reduced. $\mathrm{KC}^{*}$ also explicitly includes information about flow periodicity, a chief factor determining flexural response and unsteady boundary layer mechanisms. (Note: the asterisk denoting the modification from classically defined $\mathrm{KC}$ will henceforth be dropped for convenience and clarity.)

\section{MATERIALS AND METHODS}

A $2.4 \mathrm{~m}$ long by $1.2 \mathrm{~m}$ wide portable racetrack-style field flume was used to isolate seagrass assemblages in situ, before exposing them to controlled unidirectional, oscillatory, and combined flows. Communitywide values of $S$ were determined from the measured rate of ammonium $\left(\mathrm{NH}_{4}\right)$ and nitrate $\left(\mathrm{NO}_{3}\right)$ depletion. The vertical variability in uptake was assessed by measuring the relative concentrations of isotopically labeled nutrient tracers $\left({ }^{15} \mathrm{~N}\right.$-labeled $\mathrm{NH}_{4}{ }^{+}$and $\left.\mathrm{NO}_{3}{ }^{-}\right)$ absorbed by epiphytes colonizing the top and the bottom of canopy blades. Canopy geometry data was gathered for each assemblage. Detailed profiles of the flow both within and above each canopy were measured using a pair of acoustic Doppler velocimeters (ADVs, Vectrino $25 \mathrm{~Hz}$, NortekUSA). Flow attenuation measurements were compared to model predictions to assess the suitability of the flow model for uptake prediction.

A similar apparatus has been employed successfully in a number of previous studies (Thomas et al. 2000, Thomas \& Cornelisen 2003, Cornelisen \& Thomas 2009). Isotopically labeled nutrients have been used to measure nutrient uptake for individual organisms within a community (Cornelisen \& Thomas 2006, 2009, Morris et al. 2008), to determine the relationship between seagrass and epiphyte nutrient uptake (McRoy \& Goering 1974, Lepoint et al. 2007), and to trace distribution of nutrients among community components (Koop et al. 2001, Cornelisen \& Thomas 2006, Gribsholt et al. 2006).

\section{Site and field flume}

Experiments were conducted in late June 2007 on Old Sweat Bank (hereafter OSB, 24²48.99' N, $\left.80^{\circ} 52.1^{\prime} \mathrm{W}\right)$, a shallow carbonate bank (<2 m depth) located between Long Key and Conch Key, approximately $2 \mathrm{~km}$ offshore on the Florida Bay side of the Florida Keys (Cornelisen \& Thomas 2009). Natural, tidally driven velocities at the site range up to $0.50 \mathrm{~m} \mathrm{~s}^{-1}$ (Wang 1998), and the bank is also subject to wind-driven surface waves sourced from both the ocean and the bay direction. Benthic communities at the site are seagrass dominated (primarily Thalassia testudinum; secondarily Syringodium filiforme) though sparsely mixed with coral (Porites spp.), macro algae (e.g. Halimeda spp., Laurencia. spp., and Penicillus spp.), and sponges (Cornelisen \& Thomas 2009). Encrusting organisms colonize the vertical extent of the seagrass blades. Epiphytes were composed of diatoms, blue-green algae, particulates, red macroalgae, and coralline algae (see Cornelisen \& Thomas 2004, 2009).

In each experiment, the flume was deployed onto the benthic habitat and a $5 \mathrm{~cm}$ lip was embedded in the sediment to prevent exchange with the surrounding water, effectively creating a fluid control volume (Fig. 1). Once installed, the flume isolated $2.6 \mathrm{~m}^{2}$ of benthic community both within the $2.4 \mathrm{~m}$ long, $0.6 \mathrm{~m}$ wide working section on one side of the flume and within the turn sections at each end. Operating depth was limited by the $0.8 \mathrm{~m}$ sidewall height. Two opposing electric trolling motors were mounted in one side of the flume: a single active motor produced a steady current treatment, while alternating each motor produced an oscillatory flow treatment.

The shoot density, blade length, blade width, and blade thickness of Thalassia testudinum were mea- 


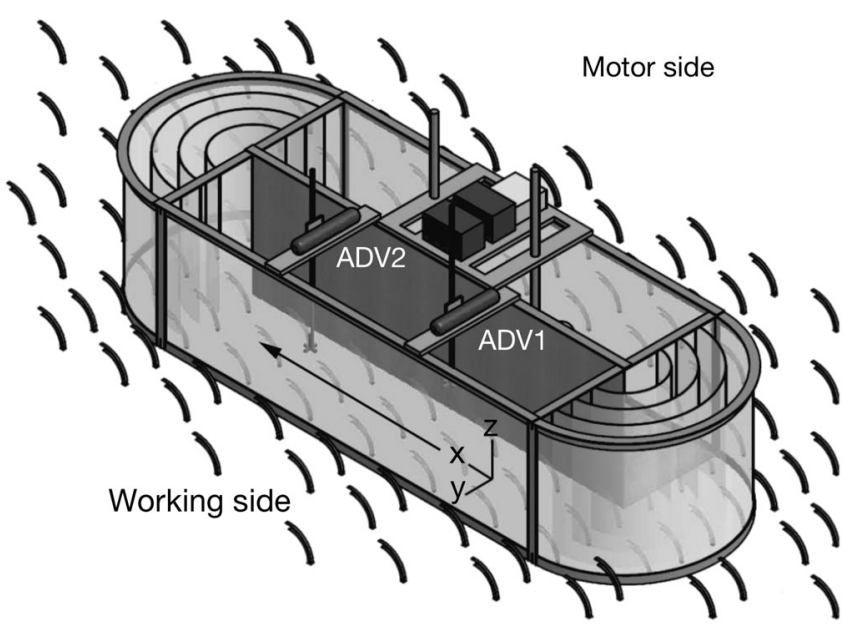

Fig. 1. Field flume used for the uptake experiments. The frame and all instrument mounts were constructed from aluminum and stainless steel structural elements; flume sides and turns were made of molded, transparent acrylic glass. The center dividing wall was a sheet of marine-grade plywood. Submersible silicone sealant was used to fill all joints. Once installed, the bottom flume edges penetrated approximately $5 \mathrm{~cm}$ into the substratum and outer walls extended up through the free water surface, creating an isolated control volume over a patch of benthic community exposed within the working side of the apparatus. Two opposing trolling motors hung down into the far side of the flume. Each motor was powered by a $12 \mathrm{~V}$ battery and controlled by a programmable timing device. Velocity both within and above the community were measured with a pair of streamwise separated acoustic Doppler velocimeters (ADV, Nortek Vectrino, $25 \mathrm{~Hz}$ )

sured for each deployment in 3 independently placed $0.25 \mathrm{~m} \times 0.25 \mathrm{~m}$ quadrats. The presence and geometry of secondary community species were likewise measured and recorded, though in the analysis that follows $T$. testudinum is used as the sole canopy representative. The effects and influences of these secondary species are considered only briefly here, with a more thorough accounting reserved for a later publication by Thomas et al.. The blade density for a seagrass canopy with shoot density $n_{\mathrm{sh}}$ and blades per shoot $b$ was approximated as $n_{\mathrm{b}}=b n_{\mathrm{sh}}$. Blade-to-blade distance $s_{\mathrm{b}}$ was then parameterized $s_{\mathrm{b}}=1 / \sqrt{n_{\mathrm{b}}}$.

\section{Uptake sample collection and processing}

At the start of each experiment, the flume water volume was spiked with a nutrient tracer of $98 \%$ ${ }^{15} \mathrm{~N}$-labeled ammonium chloride or sodium nitrate to have a final nutrient concentration of approximately $3 \mu \mathrm{mol} \mathrm{l}^{-1}$. Typical ambient concentrations at the site range between 0.1 and $0.7 \mu \mathrm{mol} \mathrm{l}^{-1}$ for ammonium and $<0.1 \mu \mathrm{mol} \mathrm{l^{-1 }}$ for nitrate (Cornelisen \& Thomas
2009). Water samples were collected continuously from a location near the motors and subsampled at regular intervals to ensure a well-mixed sample. Duplicate $30 \mathrm{ml}$ water aliquots were taken from these samples and used to determine the rate at which total DIN (both labeled and unlabeled) was removed from the water column. Typically, experiments lasted between 40 and $50 \mathrm{~min}$, and were stopped before ambient concentrations approached the saturation lower limit (see Thomas et al. 2000 for additional description of the water sampling methods).

At the end of each experiment, non-senescent Thalassia testudinum blades were collected from inside the flume and rinsed thoroughly in unlabeled seawater to halt the uptake of labeled nutrients. Epiphytes were scraped from the top $10 \mathrm{~cm}$ and from the bottom $10 \mathrm{~cm}$ of $T$. testudinum blades using the straight edge of a microscope slide (Cornelisen \& Thomas 2002). In cases when the blade length was less than $20 \mathrm{~cm}$, the blade was divided into top and bottom halves. Water and epiphyte samples were immediately transferred to ice, stored, and kept frozen until analysis. The background ${ }^{15} \mathrm{~N}$ signature of epiphytes was determined from samples collected from canopies outside of the flume at each experimental site. Previous results indicated that DIN uptake by a seagrass tissue is dependent on the degree to which it is colonized (Cornelisen \& Thomas 2004). Grass uptake values would thus reflect the combined and complicating effects of diffusive transfer and epiphytic competition. By contrast, epiphytic uptake values provide direct measures of the effectiveness of exchange.

Water samples were analyzed for DIN concentration by the University of South Florida Oceanic Nutrient Laboratory (Astoria-Pacific 305D Analyzer) and the University of Washington Oceanography Technical Services (Technicon AAII). The first-order rate constant for water column DIN depletion, $k$, was approximated by a least-squares regression of the natural log of the label concentration against time. This slope was scaled by the flume water volume, and normalized by the planar area of the community enclosed in order to calculate the uptake rate constant, $S=k V / A$ (with units of $\mathrm{m} \mathrm{s}^{-1}$ as described by Thomas et al. 2000). A threshold in $\mathrm{r}^{2}$ of 0.75 and Type I $\alpha$ of 0.05 were used to qualify regressions for further consideration.

Epiphyte samples were dried for $48 \mathrm{~h}$ at $70^{\circ} \mathrm{C}$ before grinding with a mortar and pestle in preparation for isotope analysis by the University of Hawaii Mānoa School of Oceanographic and Earth Science and Technology Isotope Laboratory (Carlo Erba 
NC2500 Elemental Analyzer; Finnigan MAT ConFloII or Finnigan MAT DeltaS). Rates of ammonium or nitrate uptake by epiphytes were calculated as the rate of ${ }^{15} \mathrm{~N}$ accumulation $\left(\mathrm{s}^{-1}\right)$ relative to the excess ${ }^{15} \mathrm{~N}$ in the water column, with units of ( $\mathrm{g} \mathrm{N}$ removed) (g N tissue) $)^{-1} \mathrm{~s}^{-1}$ (see Cornelisen \& Thomas 2006). As the epibionts scraped from the seagrass blades may have contained varying populations of photosynthetic and non-photosynthetic organisms, rates of DIN uptake by epiphytes were normalized to their nitrogen and chlorophyll content (see Cornelisen \& Thomas 2002) to provide uptake rates $(\rho)$ in units of (g N removed) (mg chl $a)^{-1} \mathrm{~s}^{-1}$.

\section{Velocity data processing}

Vertical profiles of fluid velocity were measured using $2 \mathrm{ADVs}$ installed in the test section of the flume. A dual-sensor arrangement was used to increase the vertical resolution of the profiles that could be obtained within the limited duration of each experiment. The ADVs were centered in the crossstream, separated $80 \mathrm{~cm}$ in the streamwise direction, and positioned $80 \mathrm{~cm}$ away from each flume turn. The initial height $(z)$ of the downstream sensor (ADV2) was deep within each canopy, near the bed. The upstream sensor (ADV1) started at a position roughly coinciding with the canopy top. Both instruments were started simultaneously, left in position to record data at $25 \mathrm{~Hz}$ for 3 to $5 \mathrm{~min}$, and then moved upward incrementally to collect a profile of measurements over the duration of the experiment. Record duration was varied in the oscillatory cases order to capture a sufficient number of wave periods to limit statistical uncertainty. The typical record captured more than 10 waves, though the value dropped as low as 6 in cases of especially long oscillatory period.

Real-time inspection of the velocity records was used to ensure that sensor placement minimized signal degradation from either blade obstruction or acoustic interference. In a few rare instances, small pieces of vegetation were either redirected or removed from the sample volume region of ADV2 to eliminate obstruction. Instantaneous velocity measurements with low signal correlation values $(<70 \%)$ were discarded, as were entire records with average correlation values that did not meet this criterion. The 'phase-space thresholding' technique of Goring \& Nikora (2002) was used to define, identify, and remove spikes (method improvements suggested by Wahl 2003 and discussed by Goring \& Nikora 2003 were included).
We denote instantaneous velocity in the streamwise direction $x$ at time $t$ as $u(t)$, velocity in the crossstream direction $y$ is $v(t)$, and velocity in the vertical $z$ is $w(t)$. Using a right-hand Cartesian coordinate system with $z=0$ at the bed, $z$ increases positively with upward distance from the bottom. For record of instantaneous velocities measured at height $z$ and comprised of $i=1,2,3, \ldots, \mathrm{N}$ discrete values, the associated mean velocity is:

$$
U_{\mathrm{c}}(z)=\frac{1}{N} \sum_{i=1}^{N} u_{i}(z, t)
$$

where the subscript $\mathrm{c}$ has been adopted to specify that this quantity represents the current. Turbulence is simply the instantaneous velocity variability about the time-averaged current quantity: $u^{\prime}(z, t)=u(z, t)-$ $U_{\mathrm{c}}(z)$. The time-averaged Reynolds stress is:

$$
\overline{u^{\prime} w^{\prime}}(z)=\frac{1}{N} \sum_{i=1}^{N} u^{\prime} w_{i}^{\prime}(z, t)
$$

The average magnitude of the speed of the flow, due to both steady currents and unsteady turbulent contributions, can be statistically represented with the rms quantity:

$$
U_{\mathrm{s}}(z)=\sqrt{\frac{1}{N} \sum_{i=1}^{N}\left[u_{i}(z, t)\right]^{2}}
$$

In pure unidirectional flow, $U_{\mathrm{c}} \cong U_{\mathrm{s}}$.

Ensemble averaging was used to produce timeaveraged statistics for each of the oscillatory treatments. The start of each wave was identified as the downward zero crossing of a smoothed version of each record. Each of the $M$ periodic segments or ensembles were then phase-aligned to a shared $\varphi=0$ to $2 \pi$ phase scale, Each of the M periodic segments or ensembles $(j=1,2,3, \ldots M)$ were then phase-aligned to a shared $\varphi=0$ to $2 \pi$ phase scale. This scale corresponds to $t=0$ to $T$, where $T$ is the wave period $(f=1 / T$ is the wave frequency).

Using phase-alignment, the underlying current is:

$$
U_{\mathrm{c}}(z)=\frac{1}{N_{\varphi}} \sum_{i=1}^{N_{\varphi}}\left[\frac{1}{M} \sum_{j=1}^{M} u_{i, j}(z, \varphi)\right]
$$

in which $N_{\varphi}$ is the number of individual samples in each of the $M$ ensembles. The unsteady wave component is defined to be the rms of the unsteady portion of the ensemble-averaged quantity, i.e.:

$$
U_{\mathrm{w}}(z)=\sqrt{\frac{1}{N_{\varphi}} \sum_{i=1}^{N_{\varphi}}\left(\frac{1}{M} \sum_{j=1}^{M}\left[u_{i, j}(z, \varphi)-U_{\mathrm{c}, j}(z)\right]\right)^{2}}
$$

With a sufficient number of replicated waves, the ensemble-averaging operation diminishes statistical 
variability due to turbulence; that is, turbulent contributions average to zero. The net effects of both currents and waves are represented by the rms of the full ensemble averaged quantity:

$$
U_{\mathrm{s}}(z)=\sqrt{\frac{1}{N_{\varphi}} \sum_{i=1}^{N_{\varphi}}\left[\frac{1}{M} \sum_{j=1}^{M} u_{i, j}(z, \varphi)\right]^{2}}
$$

As noted by Falter et al. (2005), combined flows can be organized by the ratio $\left|U_{\mathrm{c}}\right| / U_{\mathrm{s}}$, the value of which will vary between 0 (purely oscillatory) and 1 (purely steady) depending on the relative strength of the components. Exhibiting caution about the reliability of the wave-turbulent separation scheme, we expressly preclude detailed consideration of turbulence in the oscillatory flows.

Canopy depth-averaged velocity components were obtained by averaging along the cubic spline curve fitted to velocity measurements made between $z=0$ and the vegetation bent height, $z=h_{\mathrm{v}}$ e.g.:

$$
\widehat{U}=\frac{1}{h_{\mathrm{v}}} \int_{0}^{h_{\mathrm{v}}} U(z) d z
$$

The values at the lowest measured $z$ location were extrapolated downward to approximate the region nearest to the bed, under the assumption that the viscous bottom boundary layer thickness was negligible (Larned et al. 2004) and that wave excursions amplitudes are roughly uniform with depth (Dean \& Dalrymple 1991, Lowe et al. 2005a).

Due to canopy pronation, $h_{\mathrm{v}}$ typically lies below the heights associated with a canopy's maximum and mean measured blade lengths $\left(L_{\mathrm{b}}, l_{\mathrm{b}}\right.$, respectively). Spatial and temporal variability in canopy response made direct measurement of $h_{\mathrm{v}}$ in the field a significant challenge. Velocity profile analysis was used instead, specifying $h_{\mathrm{v}}$ in the unidirectional experiments as the surveyed height below $L_{\mathrm{b}}$ at which shear (and mean Reynolds stress) peaked. Seeking some consistency with earlier efforts (Bradley \& Houser 2009, Luhar et al. 2010), we have generally specified oscillatory $h_{\mathrm{v}}$ to be equal to $l_{\mathrm{b}}$.

\section{RESULTS}

\section{Site, uptake, and flow characterization}

Thalassia testudinum shoot density varied substantially between flume deployment locations $\left(n_{\mathrm{sh}}=58\right.$ to 459 , mean $\pm \mathrm{SD}=283 \pm 110$ shoots $\mathrm{m}^{-2}, \mathrm{n}=33$ ). Mean blade length $\left(l_{\mathrm{b}}=19.0 \pm 4.3 \mathrm{~cm}\right)$, blade width $\left(w_{\mathrm{b}}=0.9 \pm 0.1 \mathrm{~cm}\right)$, and thickness were more consistent $\left(t_{\mathrm{b}} \cong 0.1 \mathrm{~cm}\right)$. Shoots typically had between 2 and 3 blades each $\left(b=2.5 \pm 0.2\right.$ blades shoot $\left.^{-1}\right)$. The measured blade density ranged between 150 and 1373 blades $\mathrm{m}^{-2}\left(n_{\mathrm{b}}=714 \pm 294\right.$ blades $\left.\mathrm{m}^{-2}\right)$. These densities translated into $s_{\mathrm{b}}$ values between 0.027 and $0.082 \mathrm{~m}\left(s_{\mathrm{b}} / w_{\mathrm{b}}\right.$ values between 3 and 9$)$.

Significant regressions for $S$ were calculated in 25 of the experiments (Table 1): 13 of the 17 unidirectional experiments ( 7 of which tested $\mathrm{NH}_{4}{ }^{+}$uptake, 6 of which tested $\mathrm{NO}_{3}{ }^{-}$uptake, all denoted with a leading $\mathrm{U}$ ) and 12 of the 16 oscillatory experiments (all of which tested $\mathrm{NH}_{4}{ }^{+}$uptake, all denoted with a leading W). The measured canopy uptake rates $\left(S_{\mathrm{NH}_{4}}=4.3\right.$ to $27.4 \times 10^{-5} \mathrm{~m} \mathrm{~s}^{-1}, S_{\mathrm{NO}_{3}}=6.2$ to $12.8 \times 10^{-5} \mathrm{~m} \mathrm{~s}^{-1}$ ) were consistent with results from earlier studies at this site (Cornelisen \& Thomas 2009) and in line with measurement from other Thalassia testudinum communities (Thomas et al. 2000, Thomas \& Cornelisen 2003, Cornelisen \& Thomas 2006).

Top and bottom epiphyte DIN uptake rates $\left(\rho_{\text {top }}\right.$ and $\rho_{\text {bot }}$ ) were successfully measured in 24 of the experiments: 13 of the 17 unidirectional experiments and 11 of the 16 oscillatory experiments. These 13 unidirectional experiment replicates are identical to those found to have significant regressions for $S$, above. Epiphytic uptake of $\mathrm{NH}_{4}{ }^{+}$spanned values from $\rho=2.7$ to $47.8 \times 10^{-11} \mathrm{~g} \mathrm{~N}(\mathrm{mg} \mathrm{chl} a)^{-1} \mathrm{~s}^{-1}$, while uptake of $\mathrm{NO}_{3}{ }^{-}$spanned values from $\rho=1.0$ to $13.0 \times$ $10^{-11} \mathrm{~g} \mathrm{~N}(\mathrm{mg} \operatorname{chl} a)^{-1} \mathrm{~s}^{-1}$. Biomass of epiphytes on tops of blades were on average 9 times higher than that of those on the bottoms of blades (tops mean $=0.012 \pm 0.003 \mathrm{~g} \mathrm{~cm}^{-2}$ of blade, bottoms mean $=0.0018 \pm 0.0012 \mathrm{~g} \mathrm{~cm}^{-2}$ of blade) .

Example composite profiles of time- and ensemble-averaged streamwise flow statistics for a unidirectional and an oscillatory flow experiment (U3 and W3, respectively) are shown in Fig. 2. For clarity, $U_{\mathrm{s}}$ points have been omitted from the unidirectional profile, since $U_{\mathrm{s}} \cong U_{\mathrm{c}}$ for steady flows. Error bars in this figure and in those following indicate estimated combined standard uncertainty of each velocity statistic, multiplied by the appropriate coverage factors to approximate $95 \%$ confidence intervals (CI). Points appearing to lack error bars simply cover their plotted symbol-scale CI. Middepth discontinuity between upper and lower water column velocity measurements are associated with streamwise flow development and canopy pronation differences between the 2 streamwise sensor locations. Horizontal lines have been used to indicate measured blade lengths and mean water surface heights. Unidirectional velocity pro- 
Table 1. Canopy, flow, and uptake measurements from each of 33 flume experiments conducted in June 2007 at Old Sweat Bank, Florida Keys. A solid line separates oscillatory and unidirectional experiments. The dashed line divides ammonium and nitrate experiments. $U_{\infty, \mathrm{w}}$ and $T$ are strictly oscillatory parameters and have been marked as empty cells in each unidirectional row. Uptake values only appear for experiments for which uptake rate regressions were found to be significant. For definition of the parameters here and subsequently, see Appendix 2

\begin{tabular}{|c|c|c|c|c|c|c|c|c|c|c|c|c|c|}
\hline & $\begin{array}{c}\text { Expt. } \\
\text { no. }\end{array}$ & $\begin{array}{c}n_{\mathrm{sh}} \\
\left(\text { shoots m}^{-2} \text { ) }\right.\end{array}$ & $\begin{array}{c}n_{\mathrm{b}} \\
{\text { (blades } \mathrm{m}^{-2} \text { ) }}\end{array}$ & $\begin{array}{c}l_{\mathrm{b}} \\
(\mathrm{cm})\end{array}$ & $\begin{array}{c}h_{\mathrm{v}} \\
(\mathrm{cm})\end{array}$ & $\begin{array}{c}h_{\mathrm{w}} / h_{\mathrm{v}} \\
\text { (no.) }\end{array}$ & $\begin{array}{c}U_{\infty, \mathrm{s}} \\
\left(\mathrm{cm} \mathrm{s}^{-1}\right)\end{array}$ & $\begin{array}{c}U_{\infty, \mathrm{c}} \\
\left(\mathrm{cm} \mathrm{s}^{-1}\right)\end{array}$ & $\begin{array}{c}U_{\infty, \mathrm{w}} \\
\left(\mathrm{cm} \mathrm{s}^{-1}\right)\end{array}$ & $\begin{array}{c}T \\
(\mathrm{~s})\end{array}$ & $\begin{array}{c}S \\
\left(10^{-5} \mathrm{~m} \mathrm{~s}^{-1}\right)\end{array}$ & \multicolumn{2}{|c|}{$\begin{array}{c}\rho_{\text {bot }} / \rho_{\text {top }} \\
\text { (no.) }\end{array}$} \\
\hline & W01 & 160 & 380 & 14.3 & 14.3 & 3.9 & 4.8 & 1.6 & 4.5 & 20.1 & 18.1 & 0.42 & \\
\hline & W02 & 230 & 510 & 11.7 & 11.7 & 4.6 & 15.7 & 3.0 & 15.7 & 23.4 & 21.7 & 0.62 & \\
\hline & W03 & 440 & 1200 & 26.2 & 18.0 & 2.8 & 15.6 & 8.9 & 12.8 & 43.9 & 12.9 & 0.47 & \\
\hline & W04 & 390 & 1000 & 18.0 & 15.0 & 3.5 & 13.1 & 12.8 & 2.6 & 12.4 & 26.2 & 0.50 & \\
\hline & W05 & 460 & 1100 & 23.6 & 23.6 & 2.2 & 2.8 & 2.0 & 2.0 & 18.1 & 12.1 & 0.45 & \\
\hline & W06 & 360 & 870 & 19.6 & 19.6 & 3.2 & 1.5 & 1.3 & 0.7 & 13.5 & 18.1 & 0.67 & \\
\hline & W07 & 300 & 750 & 17.6 & 17.6 & 2.9 & 12.6 & 7.7 & 10.0 & 22.0 & 14.7 & 0.39 & \\
\hline & W08 & 420 & 880 & 23.3 & 23.3 & 2.0 & 4.6 & 0.4 & 4.5 & 39.1 & 8.6 & 0.78 & \\
\hline 깅 & W09 & 400 & 1000 & 18.9 & 16.0 & 3.6 & 15.7 & 10.4 & 12.2 & 43.2 & 13.4 & 0.66 & \\
\hline$\frac{\pi}{\pi}$ & W10 & 140 & 320 & 23.6 & 23.6 & 2.6 & 2.4 & 1.6 & 1.7 & 16.5 & 15.0 & 0.73 & \\
\hline F. & W11 & 310 & 770 & 14.6 & 14.6 & 4.3 & 3.2 & 2.5 & 1.9 & 18.5 & 18.4 & 0.23 & \\
\hline$\tilde{n}^{2}$ & W12 & 400 & 1000 & 27.1 & 27.1 & 2.3 & 3.9 & 1.5 & 3.6 & 3.1 & 27.4 & - & \\
\hline 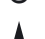 & W13 & 210 & 480 & 13.1 & 13.1 & 3.3 & 2.8 & 0.9 & 2.7 & 3.8 & - & - & \\
\hline$\uparrow$ & W14 & 300 & 880 & 18.9 & 18.9 & 2.8 & 13.3 & 11.3 & 6.9 & 5.0 & - & - & \\
\hline & W15 & 60 & 150 & 17.0 & 17.0 & 3.4 & 7.6 & 7.0 & 3.0 & 28.2 & - & - & \\
\hline & W16 & 400 & 1000 & 24.7 & 18.0 & 2.9 & 18.6 & 17.2 & 7.1 & 37.6 & - & - & \\
\hline & U01 & 230 & 510 & 11.7 & 13.5 & 4.0 & 9.6 & 9.4 & - & - & 13.7 & 0.56 & \\
\hline & U02 & 160 & 380 & 14.3 & 9.5 & 6.1 & 14.1 & 13.7 & - & - & 16.4 & 0.58 & \\
\hline & U03 & 380 & 850 & 20.5 & 12.5 & 4.3 & 16.6 & 16.2 & - & - & 14.5 & 0.29 & \\
\hline$\downarrow$ & U04 & 280 & 800 & 22.8 & 15.9 & 3.4 & 3.5 & 3.3 & - & - & 4.3 & 0.68 & 聓 \\
\hline 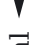 & U05 & 110 & 280 & 22.9 & 16.5 & 3.3 & 3.0 & 2.3 & - & - & 5.5 & 0.60 & \\
\hline 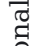 & U06 & 180 & 420 & 18.2 & 21.4 & 2.5 & 4.8 & 4.4 & - & - & 8.0 & 0.70 & $\uparrow$ \\
\hline 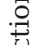 & U07 & 140 & 430 & 15.4 & 16.5 & 3.3 & 3.5 & 3.1 & - & - & 7.1 & 0.56 & \\
\hline$\stackrel{\bigcup}{d}$ & U08 & 390 & 1100 & 27.4 & 26.0 & 2.4 & 12.0 & 11.8 & - & - & - & - & \\
\hline :7] & U09 & 210 & 500 & 18.7 & 17.5 & 2.9 & 4.5 & 4.4 & - & - & 6.3 & 0.34 & \\
\hline है & U10 & 320 & 770 & 18.0 & 17.5 & 3.3 & 20.4 & 19.3 & - & - & 11.2 & 0.38 & \\
\hline & U11 & 300 & 880 & 20.6 & 21.5 & 2.3 & 3.9 & 3.7 & - & - & 7.6 & 0.13 & $\forall$ \\
\hline & U12 & 180 & 480 & 18.0 & 20.5 & 2.5 & 17.5 & 17.1 & - & - & 12.2 & 0.25 & \\
\hline & U13 & 460 & 1400 & 16.8 & 19.0 & 2.7 & 19.8 & 19.6 & - & - & 12.8 & 0.29 & Z \\
\hline & U14 & 250 & 590 & 15.5 & 18.0 & 2.7 & 3.5 & 3.2 & - & - & 6.2 & 0.29 & $\omega$ \\
\hline & U15 & 290 & 730 & 14.7 & 8.5 & 4.7 & 24.7 & 24.4 & - & - & - & - & \\
\hline & U16 & 220 & 590 & 18.1 & 17.0 & 3.0 & 13.4 & 13.0 & - & - & - & - & \\
\hline & U17 & 260 & 590 & 20.0 & 14.5 & 3.7 & 23.6 & 22.6 & - & - & - & - & \\
\hline
\end{tabular}

files consistently conformed to the canonical shear layer form of submerged canopy flow (Finnigan 2000, Luhar et al. 2008, Lacy \& Wyllie-Echeverria 2011) and resembled conditions previously measured at OSB (Cornelisen \& Thomas 2009). Oscillatory velocity profiles were similar to those measured for wave-exposed model canopies (Lowe et al. 2005a, Luhar et al. 2010). Within the canopy region, statistical variability between heights may also be attributed to differences in element proximity and associated localized flow features such as sheltering; volume-averaging would be expected to diminish such variability.

The ensemble averaging procedure produced reliable statistical estimates of the key oscillatory flow parameters. The despiked and band-pass filtered velocity records from 3 select vertical positions of the oscillatory profile shown in Fig. 2 (indicated by a, b, and $\mathrm{c}$ ) are presented in Fig. 3 to serve as visual aids to the approach. Each full velocity record $\left(a_{1}, b_{1}, c_{1}\right)$ is accompanied by a plot of its ensemble-averaged form $\left(a_{2}, b_{2}, c_{2}\right)$.

\section{Uptake and freestream flow}

Each of the oscillatory experiments conducted at OSB had a signature, dominant $T$ between 3 and $43 \mathrm{~s}$ in duration ( $f=0.023$ to $0.333 \mathrm{~Hz}$ ). $A_{\infty, \mathrm{w}}$ ranged between 0.02 and $0.89 \mathrm{~m}$, and $\mathrm{KC}$ spanned 0.35 to 31 . Of the 16 flow experiments conducted, 10 were typified by relatively low $\mathrm{KC}(0.35$ to 3.0$)$ while the 
remaining 6 had comparatively high KC (8.2 to 31). Different symbols were used to indicate results from the lowand the high-KC experiments. Based on the $\left|U_{\mathrm{C}}\right| / U_{\mathrm{s}}$ ratios, which lie between 0.08 and 0.98 , these flows are best categorized as combined (waves and currents). For ease of communication, all flows with an imposed oscillatory component will continue to be referred to as oscillatory.

As shown in Fig. 4, uptake efficiency (St) in oscillatory flows was inversely dependent on $\mathrm{KC}$ for the range of conditions tested at OSB. St decreased as excursion lengths grew and $\mathrm{KC}$ values approached the unidirectional limit (Fig. 4). Least-squares power-law regression of the data produced a fit in which $\mathrm{St} \propto \mathrm{KC}^{-0.5 \pm 0.2}$ $\left(\mathrm{r}^{2}=0.85, \mathrm{n}=11, \pm 95 \% \mathrm{CI}\right.$ indicated). A single outlier was excluded from this fitting (W4). This outlier and other points specifically labeled in subsequent figures will be considered in more detail in the 'Discussion' below. Vertical error bars indicate velocity measurement uncertainty alone. The measureable uncertainty attached to each uptake value was considered comparably small (owing to the regression threshold). Still, though great care was taken throughout, procedural errors (e.g. exchange with surrounding water, spike concentration variability, nutrient residuals) may have added some unquantifiable uncertainty, and could bear some responsibility for the variability here and in the results that follow.

The St $\propto \mathrm{KC}^{-0.5}$ dependency translates into St $\propto$ $\left(S_{\mathrm{b}} / U_{\infty, \mathrm{W}} T\right)^{0.5}$ and an uptake rate relationship of:

$$
S \propto U_{\infty, \mathrm{s}}\left(\frac{S_{\mathrm{b}}}{U_{\infty, \mathrm{w}} T}\right)^{2}
$$

In cases of pure oscillatory flow, $U_{\infty, \mathrm{s}}$ and $U_{\infty, \mathrm{w}}$ would be identical, and the uptake relationship would simplify to:

$$
S \propto\left(\frac{U_{\infty, \mathrm{w}} S_{\mathrm{b}}}{T}\right)^{0.5}
$$

Canopy uptake rate constants were thus positively dependent on freestream wave velocity, canopy element spacing, and oscillation frequency.

\section{Bulk velocity}

$S$ was positively dependent on $U_{\infty, \mathrm{S}}$ for canopies subjected to steady flows (Fig. 5a). The power-law slope of the $\mathrm{NO}_{3}$ steady flow uptake rate relationship was slightly steeper $\left(S_{\mathrm{NO}_{3}} \propto U_{\infty, \mathrm{s}}^{0.6 \pm 0.4}, \mathrm{r}^{2}=0.74, \mathrm{n}=6\right)$ than found for $\mathrm{NH}_{4}$ uptake $\left(S_{\mathrm{NH}_{4}} \propto U_{\infty, \mathrm{s}}^{0.50 .3}, \mathrm{r}^{2}=0.86\right.$, $\mathrm{n}=7$ ), though in experiments with significant flow $\left(U_{\infty, \mathrm{s}}>0.05\right)$, measured $\mathrm{NH}_{4}$ uptake rate constants exceeded $\mathrm{NO}_{3}$ rates by $25 \%$ or more. Owing to the dearth of available points, confidence intervals for these slopes (and those that follow) are broad.

Uptake of $\mathrm{NH}_{4}{ }^{+}$by epiphytes situated at the top of seagrass blades was also positively dependent on $U_{\infty, s}$ for steady flows, though the slope was considerably shallower than observed for $S$ (Fig. $5 \mathrm{~b}, \rho_{\text {top, } \mathrm{NH}_{4}}$ $\propto U_{\infty, \mathrm{s}}^{0.3 \pm 0.2}, \mathrm{r}^{2}=0.71, \mathrm{n}=7$ ). Epiphyte uptake of $\mathrm{NO}_{3}$ showed no discernible $U_{\infty, 5}$ dependency, though the few available $\rho_{\text {top }, \mathrm{NO}_{3}}$ records fell below $\rho_{\text {top, } \mathrm{NH}_{4}}$ val- 

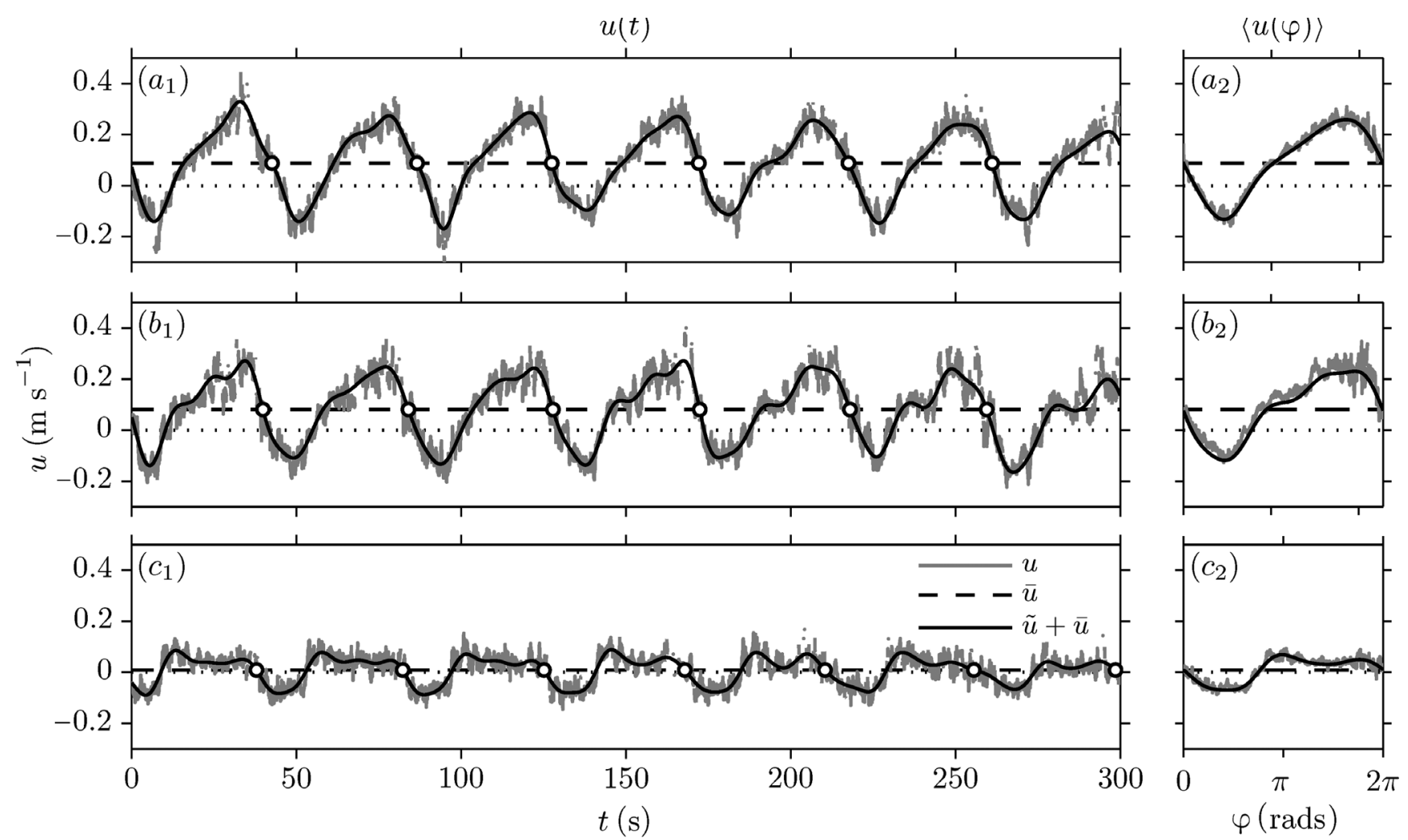

Fig. 3. Example results of the velocity processing procedure, from select heights of the oscillatory flow profile shown in Fig 2. In the left column $\left(a_{1}, b_{1}, c_{1}\right)$ despiked records of streamwise velocity $u$ are plotted respective to time, $t$. The band-pass filtered signal highlights the combined contributions of the mean current, $\bar{u}$, and the low frequency fluctuations caused by the imposed waves, $\tilde{u}$. Downward crossings of the filtered signal $(\tilde{u}+\bar{u})$ are marked with open circles. In the right column $\left(a_{2}, b_{2}, c_{2}\right)$, the ensemble averaged velocity $\langle u\rangle$ of each of these records are plotted against phase, $\varphi$

ues observed at similar $U_{\infty, s}$. Uptake rates measured at the bottom of each canopy $\left(\rho_{\text {bot }}\right)$ were not found to depend on the free-stream flow quantity (not shown).

$S$ values for oscillatory experiments conducted at both sites, as well as $\rho_{\text {top }}$ values, showed no discernible dependency on $U_{\infty, s}$ (Fig. 5a,b), though they typically far exceeded $S$ and $\rho_{\text {top }}$ values measured for unidirectional flows at comparable $U_{\infty, s}$. These results are similar to those reported by Thomas \& Cornelisen (2003), who used the mean speed rather than the rms quantity. Considered alone, neither the absolute speed nor the rms flow parameter was as effective as $\mathrm{KC}$ in describing the behavior of $S$ for oscillatory flows.

Notable, however, is an apparent division in uptake rate constants between those oscillatory flows classified as high-KC and those classified as low-KC. While $S$ and $\rho_{\text {top }}$ values for low-KC experiments deviated from the positive $U_{\infty, s}$ dependency exhibited by the unidirectional experiments, high-KC experiments appeared to conform more closely to the trendline fit of the unidirectional flow results. Indeed, in Fig. 5a, 3 high-KC oscillatory experiments in the $0.12<U_{\infty, s}<0.16 \mathrm{~m} \mathrm{~s}^{-1}$ range (near marked point W7)

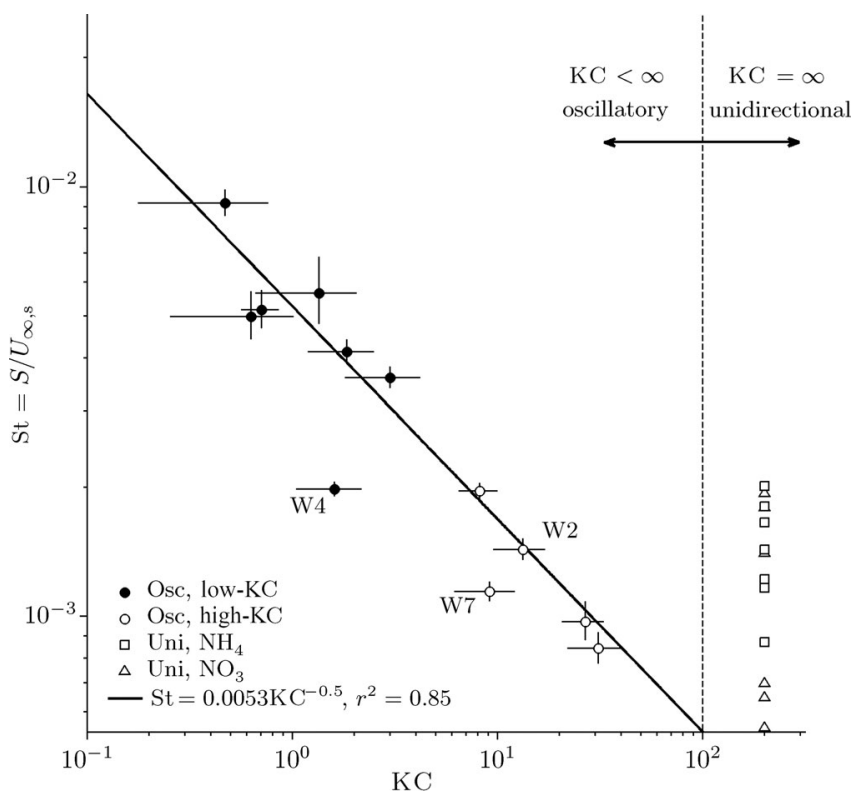

Fig. 4. Canopy $\mathrm{NH}_{4}$ uptake efficiency (Stanton number, St) plotted as a function of Keulegan-Carpenter number (KC) for oscillatory flow field-flume experiments. St values are based on rms velocity measured in the freestream $U_{\infty, \mathrm{S}}$ a statistic that encapsulates total water motion caused by both oscillatory and steady flow components 

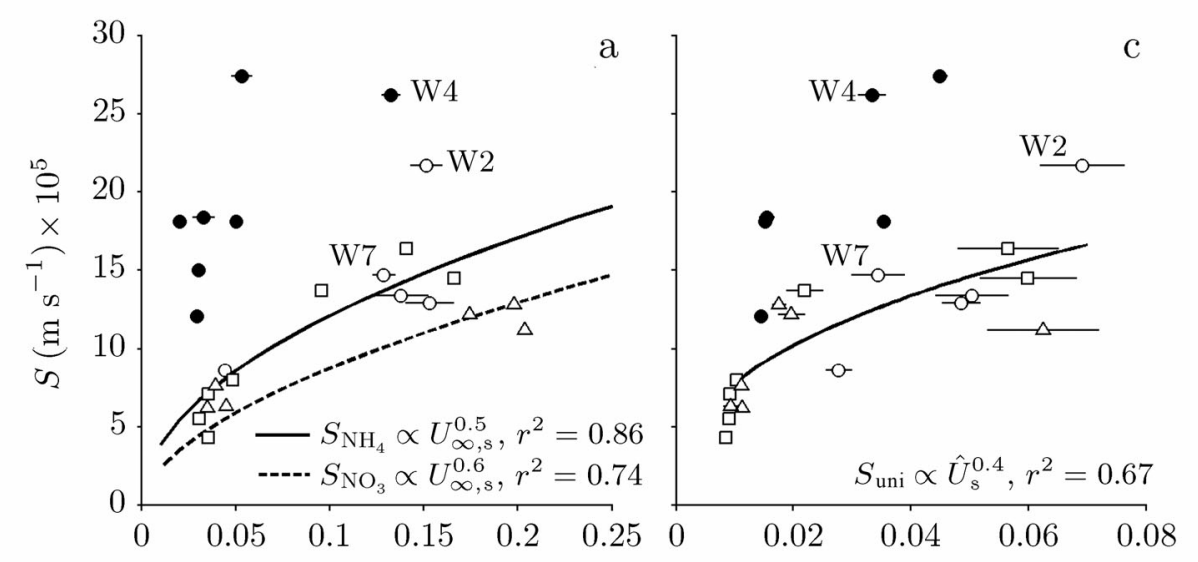

\begin{tabular}{|l|}
\hline - Osc, low-KG \\
$\circ$ Osc, high-KG \\
口 Uni, $\mathrm{NH}_{4}$ \\
$\triangle \mathrm{Uni}, \mathrm{NO}_{3}$ \\
\hline
\end{tabular}
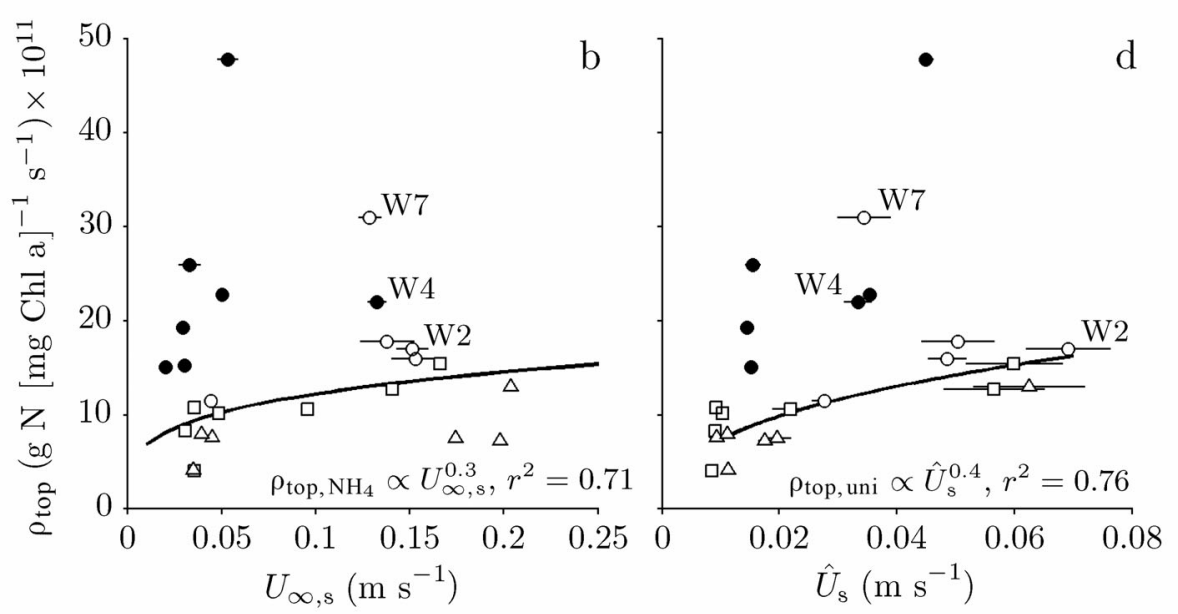

Fig. 5. Community uptake rate
constants, $S$, and epiphyte uptake
rate constants, $\rho_{\text {top, plotted as a }}$
function of $U_{\infty, \mathrm{s}}(\mathrm{a}, \mathrm{b})$ and $\widehat{U}_{\mathrm{s}}(\mathrm{c}, \mathrm{d})$.
Power law regressions show up-
take in unidirectional flow is posi-
tively dependent on $U_{\infty, \mathrm{s}}$ a result
that is consistent with previous
findings. Use of the localized flow
parameter in (c) and (d) eliminates
some of the disparity between
$\mathrm{NH}_{4}$ and $\mathrm{NO}_{3}$ flow dependencies
seen in (a) and (b)

and a fourth around $U_{\infty, \mathrm{s}}<0.05 \mathrm{~m} \mathrm{~s}^{-1}$ appeared at locations generally consistent with the unidirectional flow $S_{\mathrm{NH}_{4}}$ fit line. The same pattern of high-KC conformity with the unidirectional results repeats in Fig. 5b.

\section{Uptake and canopy flow}

Uptake rate constants were then compared using canopy depth-averaged rms velocity values $\left(\widehat{U}_{\mathrm{s}}\right)$ as measured by ADV2. Again, $S$ was positively dependent on the scale velocity for those canopies subjected to steady flows (Fig. 5c). Use of this localized flow parameter reduced the discrepancy between $\mathrm{NO}_{3}$ and $\mathrm{NH}_{4}$ uptake rate constants observed when comparing $S$ using the freestream representation (Fig. 5a). The power-law fit of all the unidirectional experiments $\left(S_{\text {uni }} \propto \widehat{U}_{\mathrm{s}}^{0.4 \pm 0.2}, \mathrm{r}^{2}=0.67, \mathrm{n}=13\right)$ was statistically indistinguishable from the fit of the $\mathrm{NH}_{4}$ uptake experiments considered alone $\left(S_{\mathrm{NH}_{4}} \propto \widehat{U}_{\mathrm{s}}^{0.5 \pm 0.3}\right.$, $\mathrm{r}^{2}=0.81, \mathrm{n}=7$ ).

Likewise, and in agreement with results presented in Fig. 5b, uptake of $\mathrm{NH}_{4}$ by epiphytes situated at the top of seagrass blades was positively dependent on $\widehat{U}_{\mathrm{s}}$ for the steady flows (Fig. $5 d, \rho_{\mathrm{top}_{1} \mathrm{NH}_{4}} \propto \widehat{U}_{\mathrm{s}}^{0.3 \pm 0.3}, \mathrm{r}^{2}=$ $0.58, \mathrm{n}=7$ ). Here also, the general discrepancy between $\mathrm{NO}_{3}$ and $\mathrm{NH}_{4}$ results was reduced $\left(\rho_{\text {top, uni }} \propto \widehat{U}_{\mathrm{s}}^{0.4 \pm 0.2}, \mathrm{r}^{2}=0.76, \mathrm{n}=13\right)$ relative to the original freestream comparison (Fig. 5b). As before, rates measured at the bottom of each canopy $\left(\rho_{\text {bot }}\right.$ ) were found to not depend on this flow quantity (not shown).

Use of $\widehat{U}_{\mathrm{s}}$ does not, however, result in a collapse of oscillatory uptake values onto the lines describing uptake for the unidirectional experiments (Fig. 5). The imposed low- and high-KC division was again instructive, though: $S$ and $\rho_{\text {top }}$ values from the high$\mathrm{KC}$ experiments were largely consistent with unidirectional flow trends while low-KC experiments were not.

\section{Vertical variation in $\rho$}

In all experiments, DIN uptake by epiphytes harvested from the upper portion of the seagrass blades was greater than uptake by epiphytes harvested from the bottom portion of the blades (i.e. $\rho_{\text {bot }} / \rho_{\text {top }}<1$, range: 0.13 to 0.78 , Fig. 6 ). The $\rho_{\text {bot }} / \rho_{\text {top }}$ ratios between were not found to depend on total flow pene- 
tration ratios $\left(\alpha_{\mathrm{s}}=\widehat{U}_{\mathrm{s}} / U_{\infty, s}\right)$, nor were they found to depend on similar ratios formed by depth averaging $U_{\mathrm{s}}$ over just the $\rho_{\text {bot }}$ zone between $z=0$ and $z=10 \mathrm{~cm}$ (not shown).

Epiphyte uptake ratios for $\mathrm{NO}_{3}$ were noticeably lower than the ratios measured for the $\mathrm{NH}_{4}$ uptake, though, regardless of the flow type considered. Focusing on just the unidirectional results - the bulk of which span a comparable and limited $\alpha_{\mathrm{s}}=0.2$ to 0.4 range $-\rho_{\text {bot }} / \rho_{\text {top }}$ values for $\mathrm{NO}_{3}{ }^{-}$were on average $50 \%$ lower than values measured for the $\mathrm{NH}_{4}{ }^{+}$species (mean $\pm \mathrm{SD}: \mathrm{NO}_{3}=0.28 \pm 0.09, \mathrm{NH}_{4}=0.56 \pm$ $0.13)$.

\section{Canopy flow attenuation}

The measured wave-component attenuation ratios $\left(\alpha_{w}\right.$, Eq. 5) declined with increasing KC (Fig. 7), a general trend that aligns with the theory covered above. Two KC-dependent model solution curves, based on 2 different canopy parameterizations, appear as gray-shaded regions behind the symbols (details in Appendix 1). The upper boundary of each

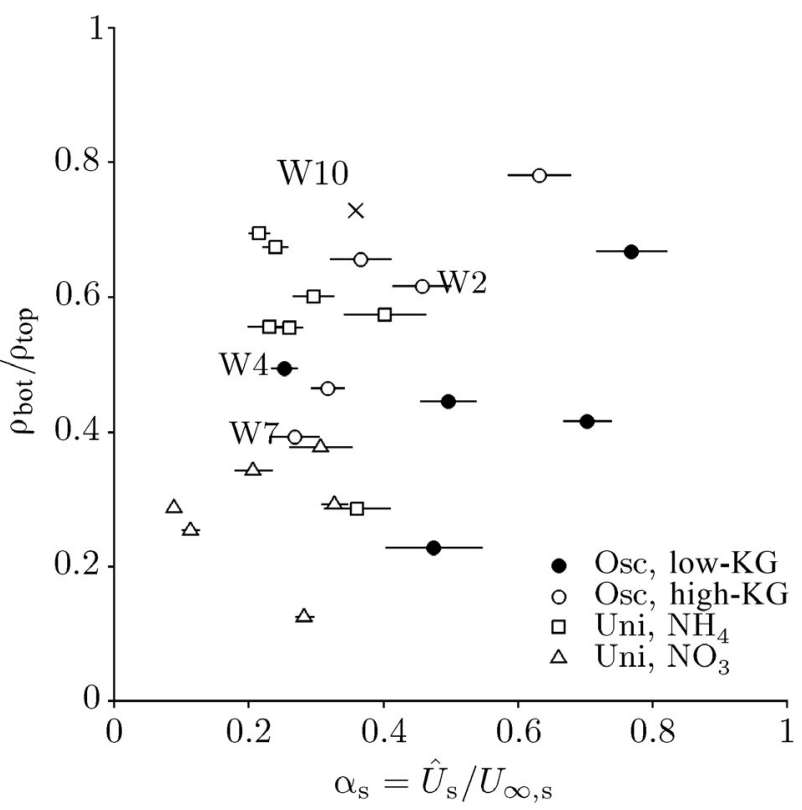

Fig. 6. Ratio comparing dissolved inorganic nitrogen (DIN) uptake rates of epiphytes situated near the bottom $\left(\rho_{\text {bot }}\right)$ and near the top $\left(\rho_{\text {top }}\right)$ of seagrass blades, compared to the ratio of flow speeds above and within each canopy $\left(\alpha_{\mathrm{s}}\right)$. The uptake ratio was always $<1$, indicating a decrease in nutrient uptake with distance from the canopy top. Though low-KC oscillatory flows generally resulted in the highest overall flow penetration values, higher $\alpha_{\mathrm{s}}$ was not correlated with larger values of the $\rho_{\text {bot }} / \rho_{\text {top }}$ ratio shaded region corresponds to the $\alpha_{\mathrm{w}}$ expected for the sparsest observed canopy at the site $\left(\lambda_{F}, \lambda_{P}\right.$ small), while the bottom edge corresponds to the $\alpha_{\mathrm{w}}$ expected for the densest canopy $\left(\lambda_{F}, \lambda_{\mathrm{P}}\right.$ large). The model solutions shown together in Fig. 7 help to depict the rough approximate range of $\alpha_{w}$ expected for flow and canopy combinations at the site. The first parameterization approximates elements as rigid strap-like blades. Such elements would occupy relatively limited planar area and-as depicted by model results - would attenuate a very small proportion of the oscillatory motion. The second parameterization approximates elements as upright cylinders with diameters equal to typical values measured at OSB. As indicated in Fig. 7, this element representation better captures the observed $\alpha_{\mathrm{w}}$ magnitudes, while significantly underestimating the current-driven flow reduction. The existing model does not factor in important flexible canopy features like flow-dependent pronation or friction scaling; it is reasonable to expect that under these limitations, a number of differing canopy parameterizations would be needed to represent the range of canopy responses.

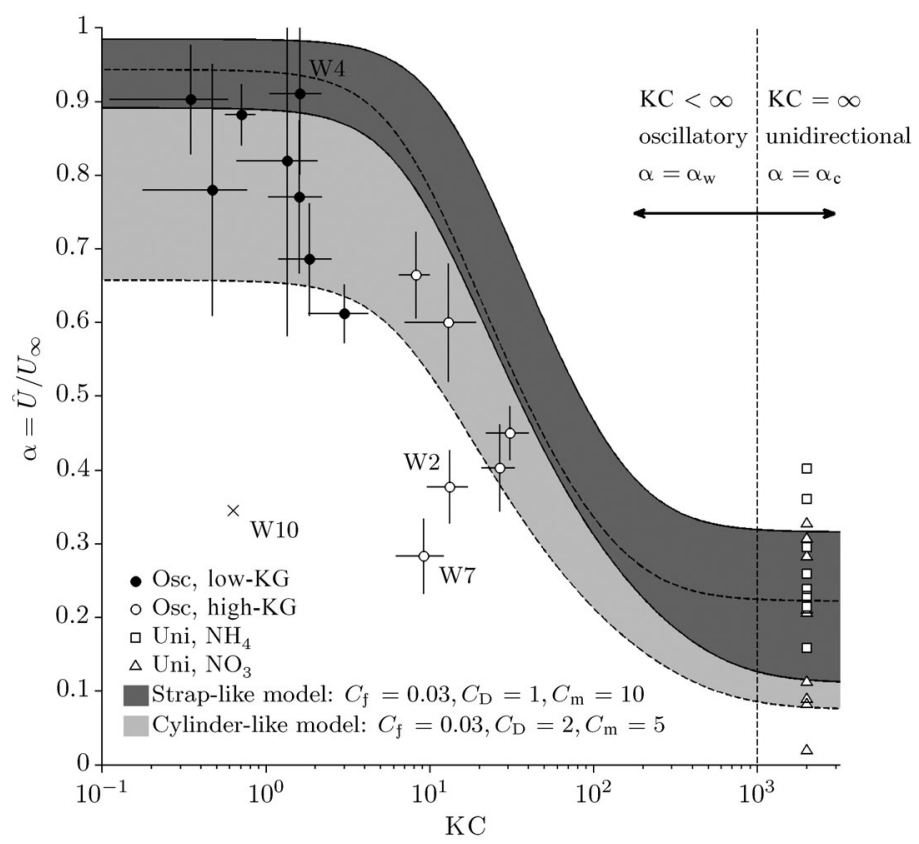

Fig. 7. The wave-component velocity ratio is inversely dependent on $\mathrm{KC}$ for the range of oscillatory flows considered here. Two model solution curves, based on 2 different canopy parameterizations, appear as gray-shaded regions behind the symbols, accentuating the expected trend of these ratios 


\section{DISCUSSION}

These experiments generated 4 distinct findings: (1) seagrass community DIN uptake rate in oscillatory flow depends on both the $U_{\mathrm{w}}$ and $f$, factors that can be represented by the modified $\mathrm{KC}$, (2) differences in $U_{\mathrm{w}}$ do not entirely account for the uptake enhancement measured in the oscillatory flows, (3) blade motion and boundary layer redevelopmenteffects that scale with the oscillatory frequencymay play a major role in this enhancement, and (4) a vertical gradient in epiphytic DIN uptake rates exists, whereby epiphytic DIN uptake decreases with depth into the canopy. This work also presents evidence that a minimally modified form of the Lowe et al. (2005a) canopy flow model can capably predict natural seagrass wave attenuation.

\section{Uptake and $\mathrm{KC}$}

For oscillatory flows, seagrass community nutrient uptake efficiency (St) increases as the orbital excursion parameter KC decreases. This relationship is theorized to encapsulate the combined effects of 3 distinct mechanisms. First, nutrient flux increases with total flow speed, a result that is consistent with current-driven mass transfer principles outlined in the 'Introduction'. Indeed, in our unidirectional experiments, both the community-wide $S$ values and the epiphyte-specific $\rho_{\text {top }}$ values increased with freestream velocity (Fig. 5a,b). Second, canopy wave attenuation is reduced as the orbital scale shrinks relative to the canopy void scale (Fig. 7), a result consistent with expectations from the canopy flow model (Lowe et al. 2005a, Luhar et al. 2010). Time-averaged velocities at the element uptake surfaces are proportionally higher in these flow conditions; surface boundary layer thicknesses would in turn be smaller. Third, as discussed earlier, both element flexural response and boundary layer disturbance increase in importance as the characteristic oscillatory period decreases. At high wave frequencies (low KC), these dynamics appear to enhance uptake substantially. As the frequency drops (high $\mathrm{KC}$ ), the role of these mechanisms is expected to diminish (Stevens et al. 2003, Huang et al. 2011).

Notably though, canopy wave attenuation was not the chief factor determining wave uptake enhancement in these experiments. While measured attenuation ratios followed trends anticipated by the model, variation in $S$ simply did not scale with the magnitude of $\widehat{U}_{\mathrm{s}}$ alone. Uptake rates in low-KC oscillatory flows were still markedly enhanced relative to unidirectional and high-KC flows with similar canopy depth-averaged flow speeds, $\widehat{U}_{\mathrm{s}}$ (Fig. 5c,d). These results run counter to theory developed and tested for rigid element mass dissolution (Falter et al. 2005, Lowe et al. 2005b, Reidenbach et al. 2006), which suggest that transfer rates for oscillatory and unidirectional flows should collapse when matched against rms quantities representing conditions close to the exchange surfaces.

However, apparent differences in the functional dependency of $S$ and $\rho_{\text {top }}$ on flow rate for each of the 2 tested DIN species were reduced when $\widehat{U}_{\mathrm{s}}$ was used as the flow reference scale (Fig. 5c,d). While this result does not conclusively address possible differences in the uptake affinity of these 2 DIN species, it highlights the importance of selecting - and then measuring or modeling - the velocities most relevant to the uptake processes under investigation. The differences between ammonium and nitrate uptake observed here are similar to those observed by Cornelisen \& Thomas (2006). Ammonium is often the preferred source of $\mathrm{N}$ as it does not require increasing enzyme activity to process it. Nitrate on the other hand requires the use of enzymes that are highly regulated. Thus, over the short term of these experiments, the organisms may not be able to respond to the increased levels of $\mathrm{N}$ and uptake of nitrate is limited by enzyme availability rather than delivery rate.

Low-KC conditions elicit a far more dynamic canopy response than expected during unidirectional and high-KC conditions. Unidirectional flows bend canopy-forming blades, 'closing' the canopy to flow intrusion and limiting element movement (Koch \& Gust 1999). Likewise, the blades in high-KC flow can respond gradually by 'going with the flow'. The motion of blades exposed to rapidly oscillating flow is expected to be more erratic (Bradley \& Houser 2009). The high-frequency of flow reversal in low-KC conditions forces regular re-orientation of canopy elements. Individual blades may remain more separated and distinct, swaying, bending, and flapping relative to water flow, thereby increasing the effective, active surface area of a given canopy.

Also, while the chief determinant of steady flow surface boundary layer thickness $(\delta)$ is the flow velocity (Larned et al. 2004), boundary layer thickness in oscillatory flows (or wave boundary layer thickness, $\delta_{\mathrm{w}}$ ) are inversely proportional to the wave frequency, or directly proportional to $T$, i.e.:

$$
\delta_{\mathrm{w}} \propto \sqrt{\frac{v T}{2 \pi}}
$$


(Dean \& Dalrymple 1991). In combined flow, the length scale is classically modeled as:

$$
\delta_{\mathrm{w}}=\kappa T \frac{u_{*}}{2 \pi}
$$

in which $u_{\text {, is }}$ the representative friction velocity and $\kappa$ is Karman's constant (Reidenbach et al. 2006). In both expressions, wave boundary layer thickness drops as the characteristic wave period decreases. The relationship found for $S$ (Eq. 19) conforms closely to these wave boundary layer principles: for a specific combined velocity, $S$ increases as the wave period shrinks, at an exponential rate consistent with the boundary layer thinning anticipated by Eq. (21). The specific nature of wave boundary layer development along these flapping, swaying, and waving blades would ultimately be governed by complex local variations in surface roughness, fluid velocity, and the relative velocity of each blade surface (Koch 1994, Denny \& Roberson 2002, Stevens et al. 2003, Huang et al. 2011). Direct investigation of boundary layer mechanics is beyond the scope of this investigation. However, evidence cited above strongly supports the contention that boundary layer thinning and redevelopment caused by wave-driven oscillations may help explain why low-KC flows show such marked uptake enhancement relative to speedmatched high-KC and unidirectional flows.

Additional mechanisms may be responsible for outliers seen in the figures. W2, for instance, had an $S$ value markedly higher than other high-KC and unidirectional experiments (Fig. 5), while the uptake efficiency of Expt W4 was low relative to other lowKC flows (Fig. 4). For example an examination of the maximum $\left(\langle\tilde{u}+\bar{u}\rangle_{\infty, \max }\right)$ and minimum $\left(\langle\tilde{u}+\bar{u}\rangle_{\infty, \min }\right)$ ensemble-averaged speed of all the experiments shows that both W2 and W4 lie toward opposing limits of the flow-reversal spectrum (Fig. 8). Experiment W2 is typified by symmetric flow reversal in which wave-driven flow passes regularly through zero to identical positive and negative extremes. In contrast, though the oscillatory component of this experiment is marked by a lower $\mathrm{KC}$ value, a strong underlying current means that velocities remain positive through each oscillatory period. Clearly, additional research into the combined effects of waves and currents, and on the importance of regular flow reversal is needed to understand these phenomena completely.

Evidence also seems to indicate that the blade density or canopy composition of Expt W7 may have been erroneously documented. St for W7 was markedly lower than expected for that experiment's KC value (Fig. 4); $\alpha_{\mathrm{w}}$ was also lower than predicted by either theory parameterization (Fig. 7). While the dependencies of $S$ on both $U_{\infty, s}$ and $\widehat{U}_{\mathrm{s}}$ for W7 were not particularly spurious (Fig. $5 \mathrm{a}, \mathrm{c}$ ), $\rho_{\text {top }}$ values were considerably greater for this experiment than for others with comparable flow conditions. Compared to other oscillatory profiles, W7 shows a sharp and immediate reduction of scaled velocity upon entry into the canopy zone (Fig. 9). Finally, measurements made within the canopies of Expts W10 and W15 were of especially poor quality. In the case of W10, all but one of the within-canopy measurement records were automatically discarded in post-processing. In W15, all the records were thus affected and $\widehat{U}_{\mathrm{s}}$ could not be determined. Points corresponding to the former experiment were marked as outliers in the 3 relevant plots. Expt W15 has been excluded throughout.

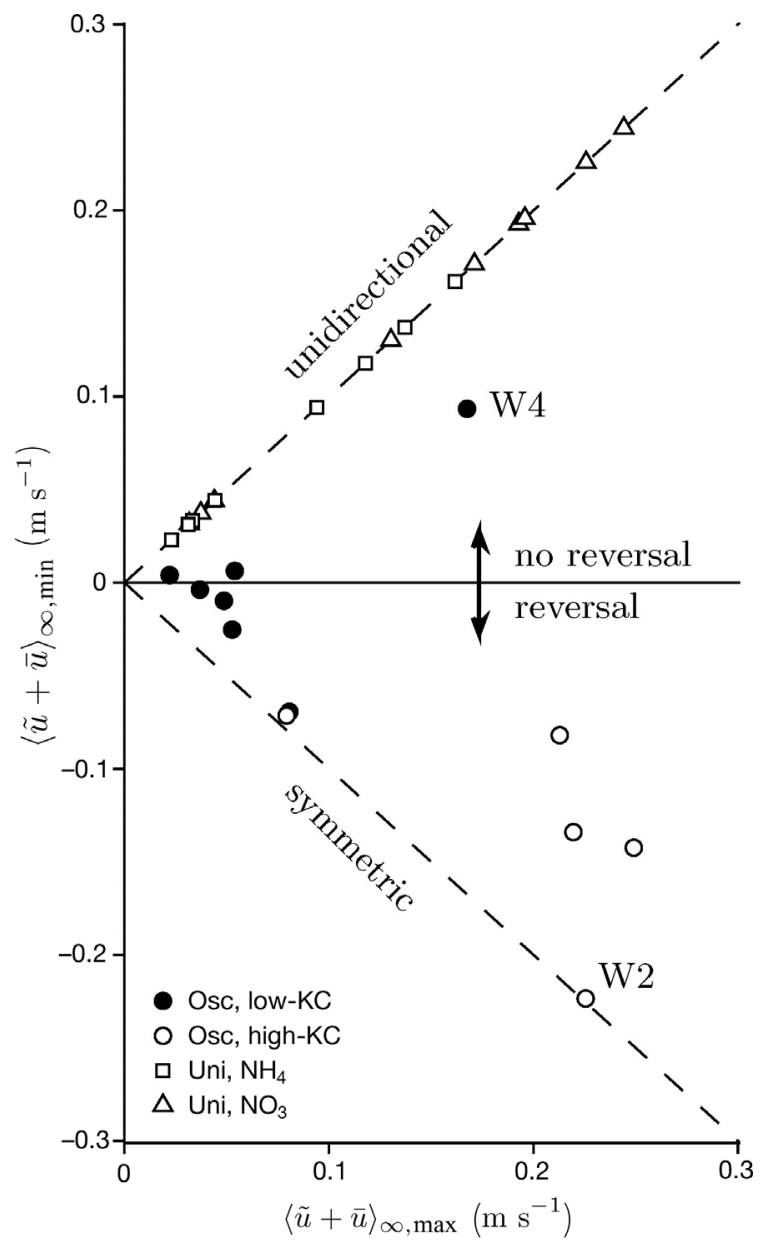

Fig. 8. Plot comparing the flow reversal in each of the experiments for which $S$ measurements we found to be significant. Here, the velocity limits are approximated by the the maximum and minimum values of the ensemble-averaged, band-pass filtered streamwise velocities in the freestream, $(\tilde{u}+\bar{u})_{\infty, \max }$ and $(\tilde{u}+\bar{u})_{\infty, \min }$, respectively. Expts W2 and W4 are notable for their comparatively large and small degree of flow reversal, respectively 


\section{Vertical gradient in epiphytic DIN uptake}

DIN uptake rates of seagrass epiphytes were found to vary with vertical position within each canopy, a result that adds important complexity to the community uptake findings. In all flow conditions, nutrient uptake was greater near the tips of blades than at their bases. The positive dependencies of $\rho_{\text {top }}$ on both $U_{\infty, s}$ and $\widehat{U}_{\mathrm{s}}$ in both unidirectional and high-KC flows closely followed the pattern found for the community uptake, $S$. Moreover, $\rho_{\text {top }}$ values for low-KC flows were greater than comparable flows from the first 2 categorizations. By contrast, DIN uptake by epiphytes in the lower portion of each canopy was not found to be dependent on either freestream or canopy depth-averaged flow statistics.

Still, while low-KC flows were found to result in less canopy flow attenuation, larger absolute $S$, and larger community uptake efficiencies than comparison flows, these results did not appear to be linked to increasing ratios of bottom-to-top epiphytic DIN uptake (Fig. 6). Indeed, there was no systematic connection between flow type and the vertical distribution of epiphytic uptake, only a general decrease of epiphytic uptake with distance from the canopy top, and an especially sharp decrease in the uptake of $\mathrm{NO}_{3}{ }^{-}$near the base of the canopy. At least in the conditions tested in this study, greater $\widehat{U}_{\mathrm{s}}$ did not result in

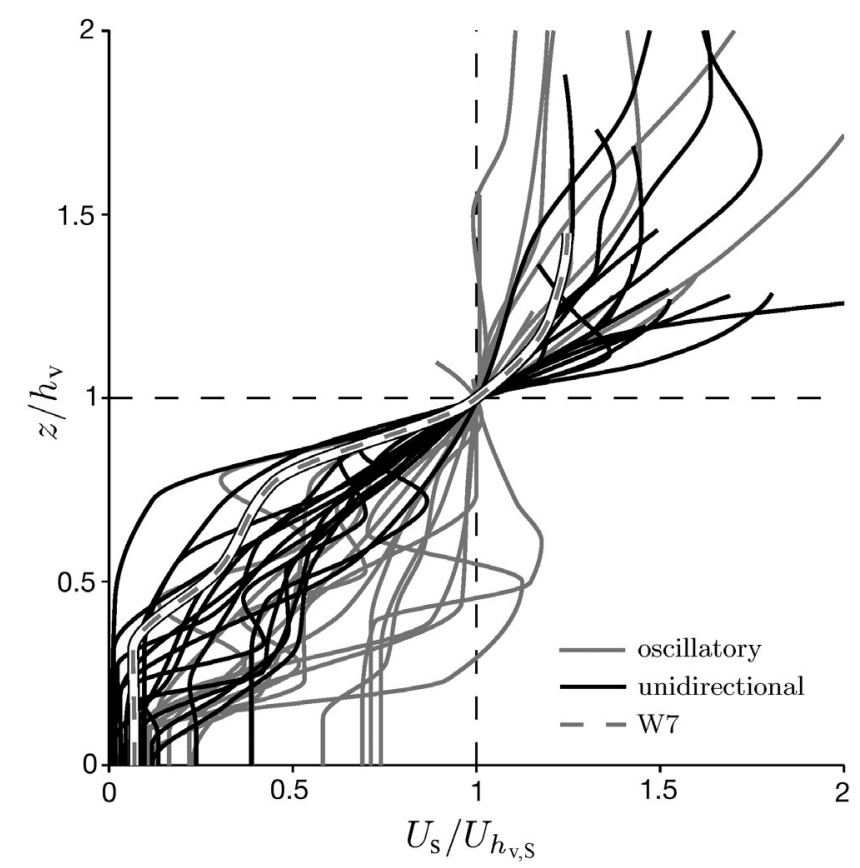

Fig. 9. Spline fit of $U_{\mathrm{s}}(z)$ measurements taken within each canopy for all oscillatory and unidirectional experiments. Heights have been normalized by $h_{\mathrm{v}}$ and velocities normalized by $U_{h_{\mathrm{V}}, \mathrm{s}}$, the velocity at the canopy top greater relative uptake activity by bottom epiphytes. Importantly, previous analysis found no detectable compositional difference among epiphytes along a blade (Cornelisen \& Thomas 2009). The ratios of chl a per tissue $\mathrm{N}$ for epiphytes from the blade top and blade bottom were not significantly different (bottoms $=0.21$, tops $=0.17, \mathrm{p}=0.11$ ).

There are numerous reasons why we may not see flow-dependent uptake in the lower regions of the canopy. The most likely reason is that while the freestream and upper-canopy velocities vary significantly between flow treatments, the resulting conditions measured toward the bottom of each canopy do not. Flows were significantly attenuated by canopy and bed resistance in the near-bed region in which the bottom halves of the blades were located. The canopy depth-averaged statistics would not reflect the vertical gradient of velocity established within each community; even higher resolution profiles would be needed to accurately represent the variation of flow conditions along the canopy height. Another possibility is that there could be undetected compositional or physiological differences in the epiphytes colonizing the top and bottom of the blades. Though while we found no significant difference between the ratio of chl a to $\mathrm{N}$ in epiphytes from each of the 2 vertical regions, a detailed genetic analysis might reveal differences not readily apparent. A third possibility is that there could be a physiological difference in response to DIN or light. While light exposure does vary somewhat in these moderate density canopies, preliminary results from shading experiments found that limiting canopy exposure to photosynthetically active radiation (PAR) had no quantifiable short-term effect on uptake rates (data not reported). The bottom of the canopy may also be exposed to higher levels of ammonium from the sediments and thus may not need to take up $\mathrm{N}$ and may be limited by some other factor. Given the high flows at the site and low density of most of the canopies, however, this mechanism seems unlikely to decrease DIN uptake to the levels seen in this experiment.

Finally, there is a possibility that the well-mixed assumption may not be satisfied under certain conditions, especially those in which flow attenuation is especially great. That is, solute concentrations within the canopy may at times fall below the benchmark value if nutrient uptake within the canopy outpaces vertical exchange with the high-concentration fluid in the freestream. However, preliminary analysis using a modified form of the scalar exchange model presented in Lowe et al. (2005b) suggested that current-driven vertical exchange was typically more 
than adequate to keep concentrations throughout the water column equal. In oscillatory flows, canopy flow attenuation is reduced, and it is reasonable to expect even greater vertical exchange occurs. A focused investigation into the presence or lack of a concentration gradient would be a welcome addition.

If overall canopy uptake rates are determined predominantly by exchange processes in the upper portion of each canopy - a conjecture that the epiphytic uptake study seems to suggest-then it is reasonable to expect that bulk flow measurements from immediately above the community remain suitable predictors of community uptake, regardless of the degree to which the flow is ultimately reduced in the lowest portions of the canopy. Still, while traditional roughsurface transport models have been able to successfully estimate the combined uptake efficiencies of benthic surfaces as complex as flexible seagrass communities, the partitioning of nutrient uptake within the canopy depends on a richer understanding of the resulting internal flow than we have yet been able to convey. Clearly, not all vertical positions and not all canopy species experience identical hydrodynamic conditions; individuals located at different heights appear to rely on different mechanisms to acquire the nutrients adequate for survival. Rare but extreme conditions (e.g. storms, floods, droughts) that preferentially benefit or stress certain species may dramatically affect the short-term uptake performance of the assemblage, a factor that may have immediate effects on community resilience. Variation in the geometric and morphological characteristics of secondary species may also influence bending dynamics, near-bed fluid velocities, and sediment deposition/resuspension.

Acknowledgements. The authors acknowledge B. Badgely, J. Dunckley, E. Hult, R. Lowe, A. Meyers, and J. Rosman for technical assistance, J. Lacy and R. Zeller for numerous helpful discussions, and S. Bell and the University of South Florida Biology Department for laboratory space and boat access. We are also indebted to our 3 anonymous reviewers, whose comments and suggestions strengthened the manuscript tremendously. This research was supported by NSF grants OCE-0715417 and OCE-0337052 to F.I.M.T. and OCE-0549835 to J.R.K. This paper is funded in part by a grant/cooperative agreement from the National Oceanic and Atmospheric Administration, Project R/HE-5, which is sponsored by the University of Hawaii Sea Grant College Program, SOEST, under Institutional Grant No. NA09OAR 4171060 from NOAA Office of Sea Grant, Department of Commerce. The views expressed herein are those of the author(s) and do not necessarily reflect the views of NOAA or any of its subagencies. UNIHI-SEAGRANT-JC-11-18. This is HIMB contribution number 1536 and SOEST contribution number 8814. J.S.W. received additional support from Stanford University's Woods Institute for the Environment.

\section{LITERATURE CITED}

Bilger R, Atkinson M (1995) Effects of nutrient loading on mass-transfer rates to a coral-reef community. Limnol Oceanogr 40:279-289

Bradley K, Houser C (2009) Relative velocity of seagrass blades: implications for wave attenuation in low-energy environments. J Geophys Res 114:F01004, doi:10.1029/ 2007JF000951

> Connolly RM, Hindell JS, Gorman D (2005) Seagrass and epiphytic algae support nutrition of a fisheries species, Sillago schomburgkii, in adjacent intertidal habitats. Mar Ecol Prog Ser 286:69-79

> Cornelisen CD, Thomas FIM (2002) Ammonium uptake by seagrass epiphytes: isolation of the effects of water velocity using an isotope label. Limnol Oceanogr 47: 1223-1229

Cornelisen CD, Thomas FIM (2004) Ammonium and nitrate uptake by leaves of the seagrass Thalassia testudinum: impact of hydrodynamic regime and epiphyte cover on uptake rates. J Mar Syst 49:177-194

> Cornelisen CD, Thomas FIM (2006) Water flow enhances ammonium and nitrate uptake in a seagrass community. Mar Ecol Prog Ser 312:1-13

> Cornelisen CD, Thomas FIM (2009) Prediction and validation of flow-dependent uptake of ammonium over a seagrass-hardbottom community in Florida Bay. Mar Ecol Prog Ser 386:71-81

Dean RG, Dalrymple RA (1991) Water wave mechanics for engineers and scientists, Vol 2. World Scientific, Singapore

Denny M, Roberson L (2002) Blade motion and nutrient flux to the kelp, Eisenia arborea. Biol Bull 203:1-13

Eggleston D, Dahlgren C, Johnson E (2004) Fish density, diversity, and size-structure within multiple back reef habitats of Key West National Wildlife Refuge. Bull Mar Sci 75:175-204

> Falter JL, Atkinson MJ, Merrifield MA (2004) Mass-transfer limitation of nutrient uptake by a wave-dominated reef flat community. Limnol Oceanogr 49:1820-1831

Falter JL, Atkinson MJ, Coimbra CFM (2005) Effects of surface roughness and oscillatory flow on the dissolution of plaster forms: evidence for nutrient mass transfer to coral reef communities. Limnol Oceanogr 50:246-254

> Finnigan J (2000) Turbulence in plant canopies. Annu Rev Fluid Mech 32:519-571

- Fonseca MS, Cahalan JA (1992) A preliminary evaluation of wave attenuation by four species of seagrass. Estuar Coast Shelf Sci 35:565-576

$>$ Fonseca MS, Fisher JS (1986) A comparison of canopy friction and sediment movement between four species of seagrass with reference to their ecology and restoration. Mar Ecol Prog Ser 29:15-22

Fry B, Parker PL (1979) Animal diet in Texas seagrass meadows: $\delta^{13} \mathrm{C}$ evidence for the importance of benthic plants. Estuar Coast Mar Sci 8:499-509

Gacia E, Granata TC, Duarte CM (1999) An approach to measurement of particle flux and sediment retention within seagrass (Posidonia oceanica) meadows. Aquat Bot 65:255-268

> Ghisalberti M, Nepf HM (2002) Mixing layers and coherent structures in vegetated aquatic flows. J Geophys Res 107:3011, doi:10.1029/2001JC000871

Goring DG, Nikora VI (2002) Despiking acoustic Doppler velocimeter data. J Hydraul Eng 128:117-126 
Goring D, Nikora V (2003) Closure to 'depiking acoustic Doppler velocimeter data' by Derek G. Goring and Vladimir I. Nikora. J Hydraul Eng 129:487-488

Gribsholt B, Struyf E, Tramper A, De Brabandere L, Brion N (2006) Nitrogen assimilation and short term retention in a nutrient-rich tidal freshwater marsh-a whole ecosystem ${ }^{15} \mathrm{~N}$ enrichment study. Biogeosciences Discuss 3: 1081-1119

Gullström M, Bodin M, Nilsson PG, Öhman MC (2008) Seagrass structural complexity and landscape configuration as determinants of tropical fish assemblage composition. Mar Ecol Prog Ser 363:241-255

> Huang I, Rominger J, Nepf H (2011) The motion of kelp blades and the surface renewal model. Limnol Oceanogr 56:1453-1462

Keulegan GH, Carpenter LH (1958) Forces on cylinders and plates in an oscillating fluid. J Res Natl Bur Stand 60: 423-440

Koch E (1994) Hydrodynamics, diffusion-boundary layers and photosynthesis of the seagrasses Thalassia testudinum and Cymodocea nodosa. Mar Biol 118:767-776

Koch E (1996) Hydrodynamics of a shallow Thalassia testudinum bed in Florida, USA. In: Kuo J, Phillips RC, Walker DI, Kirkman H (eds) Seagrass biology. Proceedings of an International Workshop, Rottnest Island, Western Australia, 25-29 January 1996. Faculty of Science, University of Western Australia, p 105-110

Koch EW, Gust G (1999) Water flow in tide- and wavedominated beds of the seagrass Thalassia testudinum. Mar Ecol Prog Ser 184:63-72

Koop K, Booth D, Broadbent A, Brodie J and others (2001) ENCORE: The effect of nutrient enrichment on coral reefs. Synthesis of results and conclusions. Mar Pollut Bull 42:91-120

Lacy JR, Wyllie-Echeverria S (2011) The influence of current speed and vegetation density on flow structure in two macrotidal eelgrass canopies. Limnol Oceanogr Fluids Environ 1:38-55

Lapointe B, Barile P, Matzie W (2004) Anthropogenic nutrient enrichment of seagrass and coral reef communities in the lower Florida Keys: Discrimination of local versus regional nitrogen sources. J Exp Mar Biol Ecol 308: 23-58

Larned ST, Nikora VI, Biggs BJF (2004) Mass-transferlimited nitrogen and phosphorus uptake by stream periphyton: a conceptual model and experimental evidence. Limnol Oceanogr 49:1992-2000

Lemmens JWTJ, Clapin G, Lavery P, Cary J (1996) Filtering capacity of seagrass meadows and other habitats of Cockburn Sound, Western Australia. Mar Ecol Prog Ser 143:187-200

Lepoint G, Jacquemart J, Bouquegneau J, Demoulin V, Gobert S (2007) Field measurements of inorganic nitrogen uptake by epiflora components of the seagrass Posidonia oceanica (Monocotyledons, Posidoniaceae). 1. J Phycol 43:208-218
Lowe RJ, Koseff JR, Monismith SG (2005a) Oscillatory flow through submerged canopies: 1 . Velocity structure. J Geophys Res 110:C10016, doi:10.1029/2004JC002788

Lowe RJ, Koseff JR, Monismith SG, Falter JL (2005b) Oscillatory flow through submerged canopies: 2. Canopy mass transfer. J Geophys Res 110:C10017, doi:10.1029/ 2004JC002789

Luhar M, Rominger J, Nepf H (2008) Interaction between flow, transport and vegetation spatial structure. Environ Fluid Mech 8:423-439

Luhar M, Coutu S, Infantes E, Fox S, Nepf H (2010) Wave induced velocities inside a model seagrass bed. J Geophys Res 115:C12005, doi:10.1029/2010JC006345

McRoy CM, Goering JJ (1974) Nutrient transfer between the seagrass Zostera marina and its epiphytes. Nature 248: 173-174

Moncreiff CA, Sullivan MJ, Daehnick AE (1992) Primary production dynamics in seagrass beds of Mississippi Sound: the contributions of seagrass, epiphytic algae, sand microflora, and phytoplankton. Mar Ecol Prog Ser 87:161-171

> Monismith SG (2007) Hydrodynamics of coral reefs. Annu Rev Fluid Mech 39:37-55

Morris E, Peralta G, Brun F, Van Duren L, Bouma T, PerezLlorens J (2008) Interaction between hydrodynamics and seagrass canopy structure: spatially explicit effects on ammonium uptake rates. Limnol Oceanogr 53: 1531-1539

Nishihara GN, Ackerman JD (2009) Diffusive boundary layers do not limit the photosynthesis of the aquatic macrophyte Vallisneria americana at moderate flows and saturating light levels. Limnol Oceanogr 54:1874-1882

> Reidenbach M, Koseff J, Monismith S, Steinbuck J, Genin A (2006) The effects of waves and morphology on mass transfer within branched reef corals. Limnol Oceanogr 51:1134-1141

Stevens CL, Hurd CL, Isachsen PE (2003) Modelling of diffusion boundary-layers in subtidal macroalgal canopies: the response to waves and currents. Aquat Sci 65:81-91

Szmant A, Forrester A (1996) Water column and sediment nitrogen and phosphorus distribution patterns in the Florida Keys, USA. Coral Reefs 15:21-41

- Thomas FIM, Atkinson MJ (1997) Ammonium uptake by coral reefs: effects of water velocity and surface roughness on mass transfer. Limnol Oceanogr 42:81-88

> Thomas FIM, Cornelisen CD (2003) Ammonium uptake by seagrass communities: effects of oscillatory versus unidirectional flow. Mar Ecol Prog Ser 247:51-57

Thomas FIM, Cornelisen CD, Zande JM (2000) Effects of water velocity and canopy morphology on ammonium uptake by seagrass communities. Ecology 81:2704-2713

Wahl TL (2003) Discussion of 'Despiking acoustic doppler velocimeter data' by Derek G. Goring and Vladimir I. Nikora. J Hydraul Eng 129:484-487

> Wang J (1998) Subtidal flow patterns in western Florida Bay. Estuar Coast Shelf Sci 46:901-915 
Appendix 1. Canopy flow model

The Lowe et al. (2005a) model predicts canopy depthaveraged velocity $(\widehat{U})$ using information from freestream flow conditions, canopy geometry, and parameterized drag and shear statistics. In the most general case, for oscillatory flow described by a rms wave velocity $\left(\widehat{U}_{\infty, \mathrm{w}}\right)$ with a dominant periodicity $(T)$, the expression:

$$
i(\beta-1)=\frac{8}{3 \pi} \frac{A_{\infty, \mathrm{w}}}{L_{\mathrm{S}}}-\frac{8}{3 \pi} \frac{A_{\infty, \mathrm{w}}}{L_{\mathrm{D}}}|\beta| \beta-i\left(\frac{C_{\mathrm{m}} \lambda_{\mathrm{P}}}{1-\lambda_{\mathrm{P}}}\right) \beta
$$

must be solved for the complex variable $\beta$, from which $\alpha_{\mathrm{w}}$ $=|\beta|$, and therefore $\widehat{U}_{\mathrm{w}}=\widehat{U}_{\infty, \mathrm{w}} \alpha_{\mathrm{w}}$ (Luhar et al. 2010). Here, $C_{\mathrm{m}}$ is the inertial force coefficient of a typical canopy element. The characteristic length scales of the shear force is:

$$
L_{\mathrm{S}}=\frac{2 h_{\mathrm{v}}}{C_{\mathrm{f}}}
$$

where $h_{\mathrm{v}}$ is the height of the canopy, and $C_{\mathrm{f}}$ is the canopy friction coefficient. The characteristic length scale of the drag force is:

$$
L_{\mathrm{D}}=\frac{2 h_{\mathrm{v}}\left(1-\lambda_{\mathrm{P}}\right)}{C_{\mathrm{D}} \lambda_{\mathrm{F}}}
$$

in which $C_{\mathrm{D}}$ is coefficient of drag and the wave orbital excursion distance $A_{\infty, \mathrm{w}}$ appears as Eq. (10).

In conditions for which $A_{\infty, \mathrm{w}} \ll L_{\mathrm{S}}$ and $A_{\infty, \mathrm{w}} \ll L_{\mathrm{D}}$, flow is dominated by inertial forces, the first 2 terms on the right hand side of Eq. (A1) become negligible, and the governing relationship simplifies to:

$$
\alpha_{i}=\frac{1-\lambda_{\mathrm{P}}}{1+\left(C_{\mathrm{m}}-1\right) \lambda_{\mathrm{P}}}
$$

Likewise, when $A_{\infty, \mathrm{w}}$ becomes large relative to $L_{\mathrm{S}}$ and $L_{\mathrm{D}}, \alpha$ reaches a current-dominated lower limit reflected as a balance of canopy shear and drag:

$$
\alpha_{\mathrm{c}}=\sqrt{\frac{L_{\mathrm{D}}}{L_{\mathrm{S}}}}
$$

As this solution covers conditions for which $A_{\infty, \mathrm{w}} \rightarrow \infty$, this representation can be used to predict steady canopy flow caused by imposed currents.

The total bed area per blade can be described as $\mathrm{A}_{\mathrm{T}}=$ $s_{\mathrm{b}}^{2}=1 / n_{\mathrm{b}}$. Thalassia testudinum blades are 'strap-like', with rectangular cross-section $\left(w_{\mathrm{b}} » t_{\mathrm{b}}\right)$. Frontal area per unit height was parameterized as $A_{\mathrm{F}}=w_{\mathrm{b}} h_{\mathrm{v}}$ and planar area as $A_{\mathrm{P}}=w_{\mathrm{b}} t_{\mathrm{b}}$. The $2 \lambda$ parameters are then:

$$
\lambda_{\mathrm{F}}=\frac{A_{\mathrm{F}}}{A_{\mathrm{T}}}=n_{\mathrm{b}} W_{\mathrm{b}} h_{\mathrm{v}}
$$

and:

$$
\lambda_{\mathrm{P}}=\frac{A_{\mathrm{P}}}{A_{\mathrm{T}}}=n_{\mathrm{b}} W_{\mathrm{b}} t_{\mathrm{b}}
$$

For rectangular elements that face oncoming flow with cross-stream dimension $w_{\mathrm{b}}$ and dimension $t_{\mathrm{b}}, C_{\mathrm{m}} \approx 1+$ $w_{\mathrm{b}} / t_{\mathrm{b}}$ (Luhar et al. 2010, Dean \& Dalrymple 1991). For our geometry, $C_{\mathrm{m}} \approx 10$. This scaling contrasts with the cylindrical element geometry used in Lowe et al. (2005a) and the rigid model stems explored in Luhar et al. (2010), for which, $\lambda_{\mathrm{P}}=\pi d^{2} / 4, C_{\mathrm{m}} \approx 2$.

Typical $C_{\mathrm{f}}$ and $C_{\mathrm{D}}$ for these canopy and flow conditions were estimated from unidirectional flow experiments, using the parameterizations:

$$
C_{\mathrm{f}}=2\left(u_{*} h_{\mathrm{v}} / U_{\infty, \mathrm{c}}\right)^{2}
$$

and:

$$
C_{\mathrm{D}}=\frac{C_{\mathrm{f}}\left(1-\lambda_{\mathrm{P}}\right)}{\lambda_{\mathrm{F}}\left(\frac{\widehat{U}_{\mathrm{c}}}{U_{\infty, \mathrm{c}}}\right)}
$$

Here, the friction velocity was taken to be $u_{{ } h_{\mathrm{v}}}=\sqrt{-\overline{u^{\prime} w^{\prime}}\left(z=h_{\mathrm{v}}\right)}$ That is, the square root of the average streamwise Reynolds stress at the top of the canopy - the peak stress location. Eq. (A9) was formed by substituting Eqs. (A2) \& (A3) into Eq. (A1) and rearranging.

For the canopy flows measured at the site, $C_{\mathrm{f}}$ ranged between 0.003 and 0.073 , with a median value of 0.017 (mean $\pm \mathrm{SD}=0.023 \pm 0.020, \mathrm{n}=16$, one outlier). All $C_{\mathrm{D}}$ values were $\mathrm{O}(1)($ median $=0.8$, mean $\pm \mathrm{SD}=1.1 \pm 1.3$, $\mathrm{n}=17$ ). These parameter values are consistent with previously reported numbers from the site (Cornelisen \& Thomas 2009). The representative solution ranges plotted in Fig. 7 were formed using each of the 2 geometries described above, along with parameters found typical at the site. Low-KC seagrass flow attenuation was greater than predicted by parameterizations based on both strap-like and ideal circular cylindrical geometry. An increase of the inertial force coefficient for the cylindrical approximation produced stronger agreement. Proper representation of these dynamic canopies in a model such as this remains an open challenge. 
Appendix 2. Variables, abbreviations and units

\begin{tabular}{|c|c|c|}
\hline$A$ & Total community planar area & $\mathrm{m}^{2}$ \\
\hline$A_{\infty, \mathrm{w}}$ & Freestream wave orbital excursion distance & $\mathrm{m}$ \\
\hline$A_{\mathrm{F}}$ & Element frontal area & $\mathrm{m}^{2}$ \\
\hline$A_{\mathrm{P}}$ & Element planar area & $\mathrm{m}^{2}$ \\
\hline$A_{\mathrm{T}}$ & Bed area per element & $\mathrm{m}^{2}$ \\
\hline$b$ & Shoot blade density & blades shoot ${ }^{-1}$ \\
\hline$C_{0}$ & Mass concentration at transfer surface & $\mu \mathrm{mol} \mathrm{l} \mathrm{l}^{-1}$ \\
\hline$C_{\infty}$ & Mass concentration in surrounding fluid & $\mu \mathrm{mol} \mathrm{l} \mathrm{l}^{-1}$ \\
\hline$C_{\mathrm{D}}$ & Drag coefficient & \\
\hline$C_{\mathrm{f}}$ & Canopy friction coefficient & \\
\hline$C_{\mathrm{m}}$ & Inertial force coefficient & \\
\hline$f$ & Wave frequency & $\mathrm{Hz}$ \\
\hline$h_{\mathrm{v}}$ & Canopy height & $\mathrm{m}$ \\
\hline$J$ & Mass flux & $\mu \mathrm{mol} \mathrm{m} \mathrm{m}^{-2} \mathrm{~s}^{-1}$ \\
\hline$k$ & Water column nutrient depletion rate & $\mathrm{s}^{-1}$ \\
\hline $\mathrm{KC}$ & Keulegan-Carpenter number & \\
\hline$l_{\mathrm{b}}$ & Mean blade length & $\mathrm{m}$ \\
\hline$L_{\mathrm{b}}$ & Maximum blade length & $\mathrm{m}$ \\
\hline$L_{\mathrm{D}}$ & Drag length scale & $\mathrm{m}$ \\
\hline$L_{\mathrm{S}}$ & Shear length scale & $\mathrm{m}$ \\
\hline$n_{\mathrm{b}}$ & Blade density & blades $\mathrm{m}^{-2}$ \\
\hline$n_{\mathrm{sh}}$ & Shoot density & shoots $\mathrm{m}^{-2}$ \\
\hline $\operatorname{Re}$ & Reynolds number & \\
\hline$s$ & Element-to-element spacing scale & $\mathrm{m}$ \\
\hline$S$ & Mass transfer coefficient & $\mathrm{m} \mathrm{s}^{-1}$ \\
\hline St & Stanton number & \\
\hline$t_{\mathrm{b}}$ & Mean blade thickness & $\mathrm{m}$ \\
\hline$T$ & Wave period & $\mathrm{s}$ \\
\hline$u * h_{\mathrm{v}}$ & Canopy friction velocity & $\mathrm{m} \mathrm{s}^{-1}$ \\
\hline$U_{\infty, \mathrm{c}}$ & Freestream current velocity & $\mathrm{m} \mathrm{s}^{-1}$ \\
\hline$U_{\infty, \mathrm{s}}$ & Freestream speed & $\mathrm{m} \mathrm{s}^{-1}$ \\
\hline$U_{\infty, \mathrm{W}}$ & Freestream rms wave velocity & $\mathrm{m} \mathrm{s}^{-1}$ \\
\hline$\widehat{U}_{\mathrm{c}}$ & Canopy depth-averaged current velocity & $\mathrm{m} \mathrm{s}^{-1}$ \\
\hline$\widehat{U}_{\mathrm{s}}$ & Canopy depth-averaged speed & $\mathrm{m} \mathrm{s}^{-1}$ \\
\hline$\widehat{U}_{\mathrm{w}}^{\mathrm{s}}$ & Canopy depth-averaged rms wave velocity & $\mathrm{m} \mathrm{s}^{-1}$ \\
\hline$V$ & Flume water volume & $\mathrm{m}^{3}$ \\
\hline$w_{\mathrm{b}}$ & Mean blade width & $\mathrm{m}$ \\
\hline$\alpha$ & Canopy flow attenuation ratio & \\
\hline$\lambda_{\mathrm{F}}$ & Frontal area parameter & \\
\hline$\lambda_{\mathrm{P}}$ & Planar area parameter & \\
\hline$v$ & Kinematic viscosity & $\mathrm{m}^{2} \mathrm{~s}^{-1}$ \\
\hline$\rho$ & Epiphytic nutrient uptake rate & $\operatorname{g~N}(\operatorname{mg~chl} a)^{-1} \mathrm{~s}^{-1}$ \\
\hline$\omega$ & Orbital frequency & $\mathrm{s}^{-1}$ \\
\hline
\end{tabular}

